\title{
Analysis of co-isogenic prion protein deficient mice reveals behavioral deficits, learning impairment, and enhanced hippocampal excitability
}

\author{
A. Matamoros-Angles ${ }^{1,2,3,4,5 \dagger}$, A. Hervera ${ }^{1,2,3,4 \dagger}$, J. Soriano ${ }^{6,7}$, E. Marti ${ }^{1,9}$, P. Carulla ${ }^{1,2,3}$, F. Llorens ${ }^{3,10,11}$, \\ M. Nuvolone ${ }^{12,13}$, A. Aguzzi ${ }^{12}$, I. Ferrer ${ }^{3,4,14,15}$, A. Gruart ${ }^{16}$, J. M. Delgado-García ${ }^{16^{*}}$ and J. A. Del Río $1,2,3,4^{*}$
}

\begin{abstract}
Background: Cellular prion protein $\left(\mathrm{PrP}^{\mathrm{C}}\right)$ is a cell surface GPI-anchored protein, usually known for its role in the pathogenesis of human and animal prionopathies. However, increasing knowledge about the participation of $\operatorname{PrP}^{C}$ in prion pathogenesis contrasts with puzzling data regarding its natural physiological role. $\operatorname{PrP}{ }^{C}$ is expressed in a number of tissues, including at high levels in the nervous system, especially in neurons and glial cells, and while previous studies have established a neuroprotective role, conflicting evidence for a synaptic function has revealed both reduced and enhanced long-term potentiation, and variable observations on memory, learning, and behavior. Such evidence has been confounded by the absence of an appropriate knock-out mouse model to dissect the biological relevance of $\operatorname{PrP}^{C}$, with some functions recently shown to be misattributed to $\operatorname{PrP}^{C}$ due to the presence of genetic artifacts in mouse models. Here we elucidate the role of PrPC in the hippocampal circuitry and its related functions, such as learning and memory, using a recently available strictly co-isogenic Prnp ${ }^{0 / 0}$ mouse model $\left(\right.$ Prnp $\left.^{\mathrm{ZH} 3 / 2 \mathrm{ZH} 3}\right)$.
\end{abstract}

Results: We performed behavioral and operant conditioning tests to evaluate memory and learning capabilities, with results showing decreased motility, impaired operant conditioning learning, and anxiety-related behavior in $\mathrm{Prnp}^{\mathrm{ZH} 3 / \mathrm{ZH} 3}$ animals. We also carried in vivo electrophysiological recordings on CA3-CA1 synapses in living behaving mice and monitored spontaneous neuronal firing and network formation in primary neuronal cultures of $\operatorname{Prnp}{ }^{\mathrm{ZH} 3 / \mathrm{ZH} 3}$ vs wildtype mice. PrPC absence enhanced susceptibility to high-intensity stimulations and kainateinduced seizures. However, long-term potentiation (LTP) was not enhanced in the Prnp ${ }^{2 H 3 / 2 H 3}$ hippocampus. In addition, we observed a delay in neuronal maturation and network formation in Prnp ${ }^{2 \mathrm{H} 3 / \mathrm{ZH} 3}$ cultures.

\footnotetext{
*Correspondence: jmdelgar@upo.es; jadelrio@ibecbarcelona.eu

${ }^{\dagger}$ A. Matamoros-Angles and A. Hervera contributed equally to this work.

${ }^{16}$ Division of Neurosciences, Pablo de Olavide University, 41013 Seville, Spain

${ }^{1}$ Molecular and Cellular Neurobiotechnology, Institute of Bioengineering of

Catalonia (IBEC), Parc Científic de Barcelona, Barcelona, Spain

Full list of author information is available at the end of the article
}

C C The Author(s). 2021 Open Access This article is licensed under a Creative Commons Attribution 4.0 International License, which permits use, sharing, adaptation, distribution and reproduction in any medium or format, as long as you give appropriate credit to the original author(s) and the source, provide a link to the Creative Commons licence, and indicate if changes were made. The images or other third party material in this article are included in the article's Creative Commons licence, unless indicated otherwise in a credit line to the material. If material is not included in the article's Creative Commons licence and your intended use is not permitted by statutory regulation or exceeds the permitted use, you will need to obtain permission directly from the copyright holder. To view a copy of this licence, visit http://creativecommons.org/licenses/by/4.0/ The Creative Commons Public Domain Dedication waiver (http://creativecommons.org/publicdomain/zero/1.0/) applies to the data made available in this article, unless otherwise stated in a credit line to the data. 
Conclusion: Our results demonstrate that $\operatorname{PrP}^{C}$ promotes neuronal network formation and connectivity. PrPC mediates synaptic function and protects the synapse from excitotoxic insults. Its deletion may underlie an epileptogenic-susceptible brain that fails to perform highly cognitive-demanding tasks such as associative learning and anxiety-like behaviors.

Keywords: Cellular prion protein, Epilepsy, Hippocampus, Behavior, Anxiety, LTP

\section{Background}

Cellular prion protein $\left(\operatorname{PrP}^{\mathrm{C}}\right)$ is a cell surface glycosylphosphatidylinositol (GPI) anchored protein expressed in several tissues with high levels in the nervous system. It is expressed ubiquitously in the brain, especially in neurons and glial cells [1-5]. $\operatorname{PrP}^{\mathrm{C}}$ is known for its crucial role in the pathogenesis of human and animal prionopathies [6, 7]. In these diseases, $\operatorname{PrP}^{\mathrm{C}}$ is transformed into a misfolded $\beta$-sheet-rich isoform, the infectious prion protein $\left(\mathrm{PrP}^{\mathrm{Sc}}\right)$ [6]. Increasing knowledge about the participation of $\operatorname{PrP}^{\mathrm{C}}$ in prion pathogenesis contrasts with puzzling data regarding its natural physiological role/s [8-10]. Indeed, this controversy was also strengthened by the absence, until a few years ago, of an appropriate $\operatorname{Prnp}^{0 / 0}$ mouse model without $\operatorname{PrP}^{\mathrm{C}}$ protein, with high breeding capability to dissect biological relevance in specific processes $[9,11-13]$.

$\mathrm{PrP}^{\mathrm{C}}$ has been previously described as neuroprotective, mainly by using loss-of-function approaches [14-16], while in other studies, $\mathrm{PrP}^{\mathrm{C}}$ overexpression was associated with increased susceptibility to neurotoxicity and cell death [15, 17-19]. This might mean that Prnp levels should be constrained to a certain level to develop their natural functions $[11,15]$. This balance is altered in several injuries and neurodegenerative processes, presenting changes in mRNA and protein expression, for example, in Alzheimer's disease, dementia with Lewy bodies, some tauopathies [20, 21], human prionopathies (e.g., sporadic Creutzfeldt Jakob Disease (sCJD) [22]), and multiple sclerosis [23].

As indicated, numerous studies have explored the physiological roles of $\mathrm{PrP}^{\mathrm{C}}$ in vivo using Prnp ${ }^{0 / 0}$ mice. However, it was later demonstrated that some physiological functions were unfortunately misattributed to $\mathrm{PrP}^{\mathrm{C}}$ due to genetic artifacts generated during the production of the most commonly used knock-out model, still in use in some laboratories: the Zürich I $\left(\right.$ Prnp $\left.{ }^{Z H 1 / Z H 1}\right)$ mouse [24]. This mouse displayed a mixed background (B6129: C57BL6/J + 129Sv) and was further backcrossed with C57BL/6 J mice to generate the B6.129 mouse line $[19,25]$, and with FVB mice to generate the FVBN-Prnp ${ }^{\text {ZH1/ZH1 }}$ model [25] in order to reduce the $129 / \mathrm{Sv}$-associated genes. However, the generated lines were systematically confounded by the Prnp-linked loci polymorphic region containing numerous $129 / \mathrm{Sv}$-associated "flanking genes" (FG) close to Prnp deletion [26,
27]. In fact, after crossing Prnp ${ }^{Z H 1 / Z H 1}$ mice with C57BL/6 J for more than ten generations to reduce FG, a remnant of $\approx 2-5 \%$ of the $129 / \mathrm{Sv}$ genome markers still persisted in B6.129 mice [26, 28, 29]. Genome analysis of these models revealed that the number of FG in the chromosome 2 regions where Prnp is localized is 62, related to different functions (i.e., cancer, depression, anxiety, among others [26]). Thus, we consider that most of the physiological phenotypes attributed to the Prnp absence or overexpression, using these mouse models carrying FG, need to be revaluated and confirmed in other FG-free models. As an example, in previous studies, we and others demonstrated that these FGs masked the real neuroprotective function of $\operatorname{PrP}^{\mathrm{C}}$ against kainate (KA) administration in vivo $[19,30-32]$. Although a full description of the FG-associated effects in a null Prnp background is not available, one of these FGs is the signal regulatory protein alpha (Sirpo), an important regulator of several innate immune functions [33]. Although prion disease evolution is not modified in $\operatorname{Sirp\alpha }^{0 / 0}$ mice [34], it has been clearly demonstrated that Sirp $\alpha$ is mainly responsible for a phagocytic function previously attributed to $\operatorname{PrP}^{C}[26,27]$. The number of functions misattributed to $\operatorname{PrP}^{\mathrm{C}}$ increased when a recent study described a substrain-related dependence of $\mathrm{Cu}(\mathrm{I})$-ATPase activity among $\operatorname{Prnp}^{0 / 0}$ mice related to the $129 / \mathrm{Sv}$ FGs and not $\operatorname{PrP}^{\mathrm{C}}$ [35].

In neurons, $\operatorname{PrP}^{\mathrm{C}}$ is transported along axons [36] and enriched at the synaptic terminal, where it has been described that it interacts with some subunits of the glutamate receptors (e.g., NMDA-R, GluK2/ GluK3, GluN2D, or mGluR5), modulating their activity, and with anchoring proteins such as PSD-95 [3739]. However, due to the different mouse strains used and some experimental differences, the involvement of $\mathrm{PrP}^{\mathrm{C}}$ in neurotransmission is still elusive. For example, different studies reported reduced [40-43], normal [25], or enhanced [19, 44] long-term potentiation (LTP) in $\operatorname{Prnp}^{0 / 0}$ mice compared to wild-type mice. Following these descriptions, the consequences of Prnp absence in memory, learning, and behavior lead to variable results in studies using mice carrying FGs [24, 45-48] or not [42, 49].

In the present study, we focused our attention on reexamining some $\operatorname{PrP}^{\mathrm{C}}$ functions associated with neurotransmission, learning, and behavior, taking advantage of 
a recently generated $\operatorname{Prnp}{ }^{0 / 0}$ mouse model: the Zürich 3 $\left(\operatorname{Prnp}^{\mathrm{ZH3} / \mathrm{ZH} 3}\right)$ [50]. This co-isogenic mouse was generated in a pure $\mathrm{C} 57 \mathrm{BL} / 6 \mathrm{~J}$ background using TALEN technology [50] and it is resistant to prion infection [51]. Here we performed a set of behavioral tests to analyze Prnp ${ }^{\mathrm{ZH} 3 / \mathrm{ZH} 3}$ mouse activity, learning, and memory capabilities. In addition, basic synaptic functions, KAmediated excitability, and LTP induction were evaluated electrophysiologically in alert behaving mice. Finally, $\operatorname{PrP}^{C}$ roles during neuronal differentiation and activity were also evaluated in primary cortical cultures. Results indicate that adult Prnp ${ }^{\mathrm{ZH} 3 / \mathrm{ZH} 3}$ mice display reduced activity and anxiety-like behavior. They also fail to acquire different instrumental learning tasks. In addition, our experiments show that hippocampal CA3-CA1 Prnp ${ }^{Z H 3 / Z H 3}$ synapse fails to induce LTP, most likely due to an exacerbated endogenous excitability, further corroborated in vivo after KA administration. Lastly, our results are sustained by the observed alteration in the expression patterns of several genes associated with neuronal system function and synaptic protein-protein interactions in the Prnp ${ }^{Z H 3 / Z H 3}$ hippocampus by an RNAseq analysis and its RT-qPCR validation.

\section{Results}

The absence of $\operatorname{PrP}^{\mathrm{C}}$ has been related to deficiencies in behavior, learning, and memory in several mouse models with different results $[24,42,52,53]$. In order to evaluate the implication of $\operatorname{PrP}^{\mathrm{C}}$ in systemic behavioral tasks, we took advantage of the new knock-out model, the Prnp ${ }^{Z H 3 / Z H 3}$ mouse. First, we analyzed the nest building capacity between $\operatorname{Prnp}^{\mathrm{ZH} 3 / \mathrm{ZH} 3}$ vs. Prnp ${ }^{+/+}$mice as an indicator of mouse welfare. In contrast to Schmitz et al., where they used Prnp ${ }^{Z H 1 / Z H 1}$ mice (reviewed in [54]), results showed a slightly increased but not significantly nest-building capacity in Prnp ${ }^{Z H 3 / Z H 3}$ compared to controls $\left(\operatorname{Prnp}^{Z H 3 / Z H 3}=3.81 \pm 0.64, \mathrm{n}=7\right.$ vs. Prnp $^{+/+}=3.00$ $\pm 0.41, \mathrm{n}=7$; mean \pm S.E.M., $p=0.15$; Mann-Whitney $U$ non-parametric test) (Additional file 1: Fig. S1), suggesting that the two genotypes had similar welfare conditions [55].

\section{Reduced activity, increased thigmotaxis, and anxiety- related behavior in Prnp ${ }^{\mathrm{ZH} / \mathrm{ZH} 3}$ mice}

First, we performed the open field test to measure the general locomotor activity levels, anxiety, and willingness in knock-out mice (Fig. 1). Prnp ${ }^{+/+}$and Prnp ${ }^{Z H 3 / Z H 3}$ mice ( $n=49$ for each genotype) were individually placed (in rounds of two animals in parallel) in the open field arena for $15 \mathrm{~min}$, and their activity was evaluated on the $\mathrm{X}-\mathrm{Y}-\mathrm{Z}$ axes (Fig. 1b). Prnp ${ }^{\mathrm{ZH} 3 / \mathrm{ZH} 3}$ mice showed significantly reduced displacement in the field $\left(\mathrm{Prnp}^{+/+}=3725\right.$ \pm 93 a.u. vs. Prnp ${ }^{Z H 3 / Z H 3}=3370 \pm 95$ a.u.; $* * p=0.009$; Mann-Whitney $U$ non-parametric test) (Fig. 1c). Anxiety and stress increased the thigmotaxis behavior and the natural aversion to exploring the inner square of the field during the test [56]. Thus, to evaluate anxiety-like behavior in the Prnp ${ }^{Z H 3 / Z H 3}$ mice, we measured this thigmotaxis performance as the time spent in the center (inner region of the field) $v s$. the periphery (outer region of the field) for each mouse (Fig. 1b). Prnp ${ }^{+/+}$mice spent the same amount of time in the two regions, while Prnp ${ }^{Z H 3 / Z H 3}$ animals remained significantly more time in the periphery close to the walls, suggesting an apprehension of the center of the field that reflects an anxiety-like behavior $\left(\right.$ Prnp $^{+/+}$: Center $=303.3 \pm 14.5$ vs. Periphery $=$ $345.7 \pm 18,0$; and Prnp ${ }^{Z H 3 / Z H 3}$ : Center $=288.2 \pm 15.1$ vs. Periphery $=394.3 \pm 20.3$; mean \pm S.E.M., $p=0.071$ and $* * 0.001$ respectively; Mann-Whitney $U$ nonparametric test) (Fig. 1d). Stressed behavior was also assessed by counting the number of rearing and immobility episodes during the test. Prnp ${ }^{\text {ZH3/ZH3 }}$ mice displayed significantly fewer rearing episodes $\left(\operatorname{Prnp}^{+/+}=52\right.$ \pm 2 vs. Prnp ${ }^{Z H 3 / Z H 3}=26.6 \pm 1.7$; mean \pm S.E.M., ${ }^{* * * * *} p<$ 0,001; Mann-Whitney $U$ non-parametric test) and more immobility episodes $\left(\right.$ Prnp $^{+/+}=6.6 \pm 1.2$ vs. Prnp ${ }^{\text {ZH3/ZH3 }}$ $=12.4 \pm 0.9$; mean \pm S.E.M., ${ }^{* * * *} p<0.001$; MannWhitney $U$ non-parametric test) confirming an anxietylike behavior (Fig. 1e).

\section{Prnp ${ }^{Z H 3 / Z H 3}$ mice and Prnp ${ }^{Z H 1 / Z H 1}$ failed to acquire instrumental learning tasks}

Our next goal was to examine the capabilities of Prnp ${ }^{\mathrm{ZH} 3 / \mathrm{ZH} 3}$ mice in performing highly demanding learning tasks. Instrumental learning capabilities were tested with operant conditioning in the Skinner box $(n=$ 49 for each genotype) (Fig. 2). Collected data were compared to those obtained using Prnp ${ }^{Z H 1 / Z H 1}$ mice (Additional file 2: Fig. S2). Thirty-one percent of Prnp ${ }^{Z H 3 / Z H 3}$ mice did not reach the learning criterion (to obtain $\geq 20$ pellets for two consecutive sessions) at the end of the training session. In contrast, all Prnp ${ }^{+/+}$mice (100\%) meet the selected criterion from the 6th session (Fig. 2a). Similarly, in a second set of experiments using Prnp ${ }^{Z H 1 / Z H 1}$ mice $\left(\right.$ Prnp $^{+/+}=10$ and Prnp $\left.{ }^{Z H 1 / Z H 1}=10\right)$, $50 \%$ of $\operatorname{Prnp}^{Z H 1 / Z H 1}$ mice failed to reach the criterion, but $80 \%$ of wild-type mice reached it at the end of the sessions (Additional file 2: Fig. S2a). These results strongly suggest that mice lacking Prnp (both $\mathrm{ZH} 1$ and $\mathrm{ZH} 3$ backgrounds) present evident instrumental learning deficiencies. Also, Prnp ${ }^{+/+}$mice pressed the lever significantly more times from session 3 onwards than Prnp ${ }^{Z H 3 / Z H 3}$ animals (Session 1: Prnp $^{+/+}=7.8 \pm 1.3$ vs. $\operatorname{Prnp}^{Z H 3 / Z H 3}=11.12 \pm 1.9, p>0.99$; Session 2: Prnp $^{+/+}=$ $21.6 \pm 2.51$ vs. Prnp ${ }^{Z H 3 / Z H 3}=15.8 \pm 2.2, p>0.99$; Session 3: Prnp $^{+/+}=40.2 \pm 5.1$ vs. Prnp $^{\text {ZH3/ZH3 }}=23.3 \pm 3.2$, $* p=0.0023$; Session 4: Prnp $^{+/+}=53.0 \pm 3.9 \mathrm{vs}$. $\operatorname{Prnp}^{Z H 3 / Z H 3}=29.4 \pm 3.1{ }^{* * *} p<0.0001$; Session 5: 
a

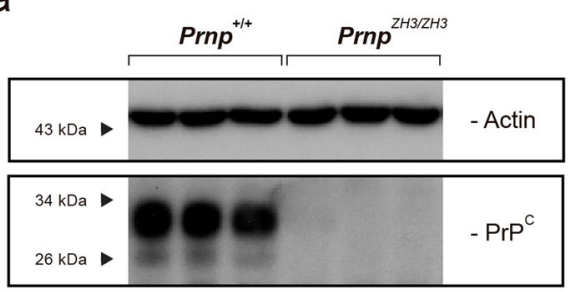

b

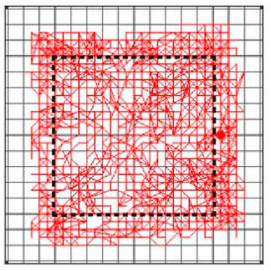

$\operatorname{Prnp}^{+/+}$

d
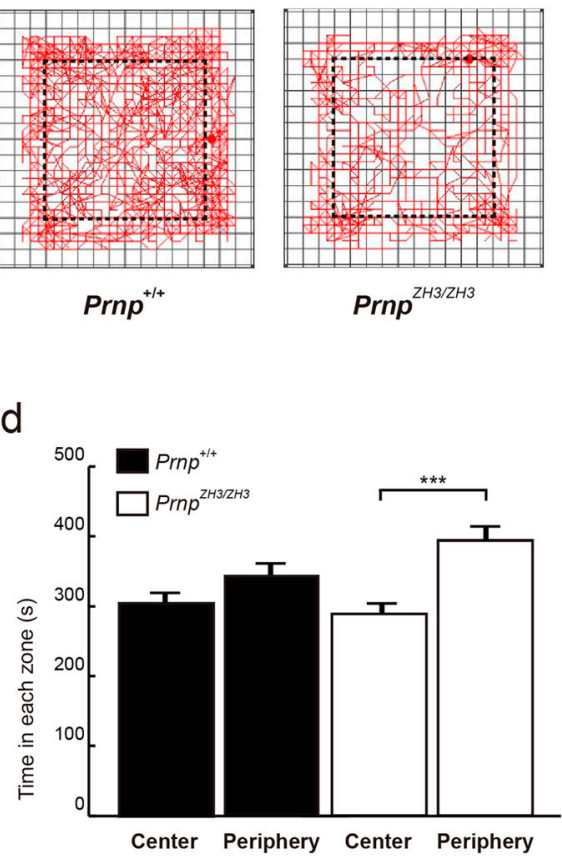

C

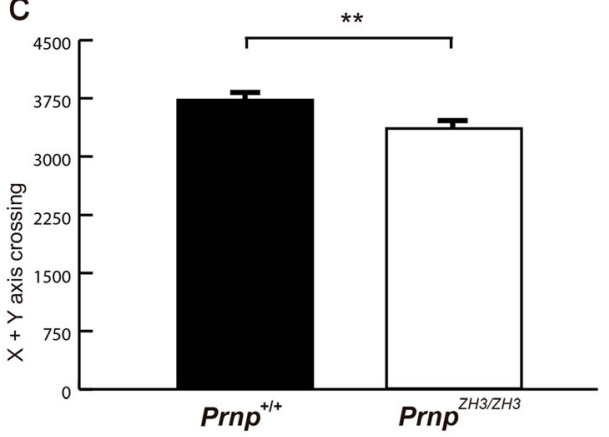

e

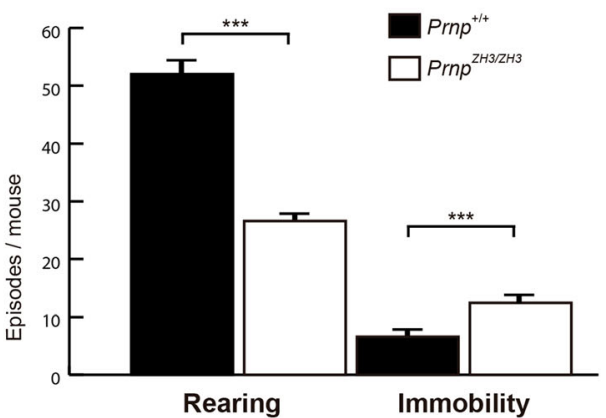

Fig. 1. $P r n p^{Z H 3 / Z H 3}$ mice show reduced activity and anxiety-related behavior. a Immunoblot analysis of $\operatorname{PrP}^{C}$ expression in $P_{r n p^{+/+}}$and $P r n p^{2 H 3 / Z H 3}$ mice forebrain. Actin is used as a loading control. b Representative images of $\operatorname{Prnp}^{+/+}$and $\operatorname{Prnp}^{\mathrm{ZH} 3 / \mathrm{ZH} 3}$ mouse exploratory behavior in the open field test. The dotted line delineates the center and the periphery of the arena. c Mouse activity in the open field test represented as the number of lines crossed in the $X+Y$-axis. $\mathbf{d}$ Time spent (s) by the mice in the center and periphery of the open field arena. e Number of rearing and immobility episodes displayed by $\mathrm{Prnp}^{+/+}$and $\mathrm{Prnp} \mathrm{Z}^{\mathrm{ZH} / \mathrm{ZH} 3}$ mice during the open field test. In total, 98 animals $(n=49$ for each genotype) were tested individually, in rounds of two animals in parallel. Data are presented as mean \pm S.E.M. ${ }^{* *} p<0.01$ and ${ }^{* *} p<0.001$, Mann-Whitney $U$ nonparametric test. Source data and individual data values are available in Additional file 10

$\operatorname{Prnp}^{+/+}=55.1 \pm 3.3$ vs. Prnp ${ }^{Z H 3 / Z H 3}=36.1 \pm 3.9$, **** $^{\text {*** }} p=$ 0.0003; Session 6: Prnp $^{+/+}=70.5 \pm 4.1$ vs. Prnp ${ }^{Z H 3 / Z H 3}=$ $38.3 \pm 3.9 * \%<0.0001$; Session $7:$ Prnp $^{+/+}=59.9 \pm 2.3$ vs $\operatorname{Prnp}^{Z H 3 / Z H 3}=39.6 \pm 3.5$, *** $p<0.0001$; two-way ANOVA + Bonferroni's multiple comparisons test) (Fig. 2b). However, as observed in the open field test, Prnp ${ }^{Z H 3 / Z H 3}$ mice presented considerable inactive behaviors (Fig. 1). To distinguish the reduction of activity from real learning deficits, 44 mice $\left(\right.$ Prnp $^{+/+}=24$ and $\operatorname{Prnp}^{Z H 3 / Z H 3}=20$ ) were subjected to a more complex operant conditioning paradigm, the light ON/light OFF task (see "Material and methods"). As expected, the total number of lever pulses during the OFF period was higher in the $\operatorname{Prnp}^{+/+}$mice and drastically reduced along with sessions (Session $1=134.8 \pm 13.3$ vs. Session $10=$ $39.7 \pm 5.2$ ) (Fig. 2c). In parallel, Prnp $^{+/+}$mice increased the number of pulses in the ON period (Session $1=26.9$ $\pm 1.8 v s$. Session $10=45.7 \pm 2.8$ ) (Fig. 2c). In contrast, Prnp ${ }^{Z H 3 / Z H 3}$ mice showed a reduced decrease of pulses in the OFF period (Session $1=73.2 \pm 11.7 v s$. Session 10 $=26.5 \pm 3.9)$ and an incipient increase in the $\mathrm{ON}$ period (Session $1=23.4 \pm 1.6$ vs. Session $10=31.1 \pm 2.9$ ) (Fig. 2d). Learning capacity, measured as the difference in the curve slope during ON or OFF periods, was drastically reduced in Prnp ${ }^{Z H 3 / Z H 3}$ mice (OFF: Prnp ${ }^{+/+}=-12.5, R^{2}$ $=0.90 ; \operatorname{Prnp}^{Z H 3 / Z H 3}=-5.9, R^{2}=0.92 ;$ ON: $\operatorname{Prnp}^{+/+}=$ 

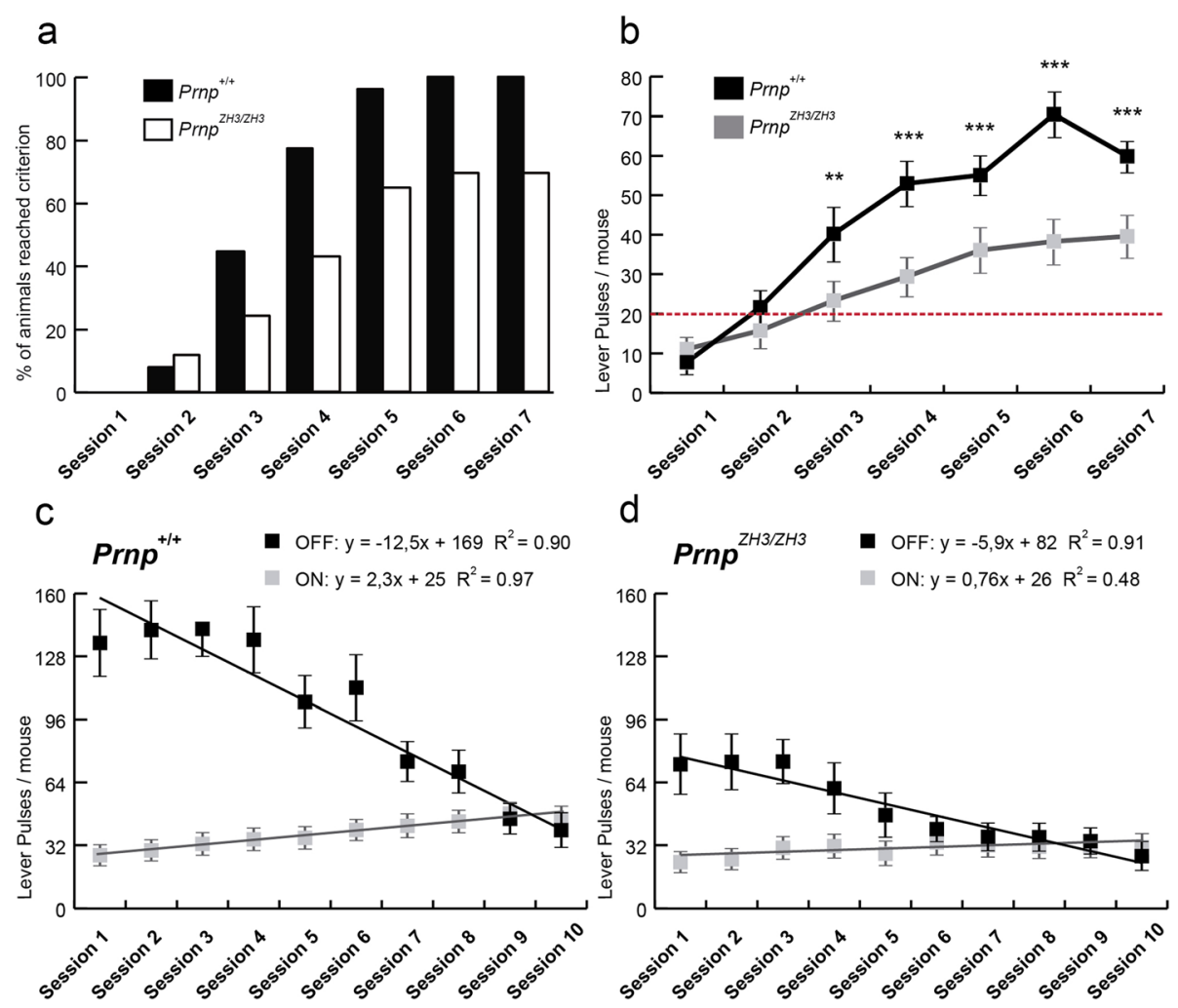

Fig. 2. Impairments in the acquisition of an instrumental learning task in Prnp $\mathrm{ZHz} / \mathrm{ZH3}$ mice. a Percentage of mice reaching the selected criterion (to collect $\geq 20$ food pellets for two consecutive days) in the successive training sessions. $\mathbf{b}$ Lever presses of Prnp ${ }^{+/+}$and Prnp ${ }^{Z H 3 / Z H 3}$ mice during the fixed ratio (1:1) conditioning paradigm. The test was performed daily for seven consecutive days. c,d Lever presses of Prnp ${ }^{+/+}$(c) and $\operatorname{Prnp}^{\mathrm{ZH} 3 / \mathrm{ZH3}}$ (d) mice during the ON/OFF training paradigm. Lines represent best linear fits for lever presses evoked during light ON (gray) and light OFF (black) periods. Equations corresponding to regression lines are illustrated in $\mathbf{c}$ and $\mathbf{d}$, including R2 coefficients. Data are presented as a percentage in $\mathbf{a}$, and as mean \pm S.E.M. in $\mathbf{b}-\mathbf{d} .{ }^{* *} p<0.01$ and ${ }^{* * *} p<0.001$, two-way ANOVA + Bonferroni's multiple comparisons test. Source data and individual data values are available in Additional file 10

2.3, $\left.R^{2}=0.96 ; \operatorname{Prnp}^{Z H 3 / Z H 3}=0.8, R^{2}=0.48\right)($ Fig. $2 \mathrm{c}, \mathrm{d}$ ). These differences show that $\operatorname{Prnp}{ }^{Z H 3 / Z H 3}$ mice failed to learn to avoid OFF periods and push the lever during the ON periods, indicating that $\operatorname{PrP}^{\mathrm{C}}$ seems to be necessary to properly acquire instrumental learning tasks. A similar study was developed using Prnp ${ }^{Z H 1 / Z H 1}$ mice, and the task accuracy ratio ((lever presses during light ON - lever presses during light OFF)/(total number of lever presses)) was evaluated. At the end of the experiment (sessions 7 and 8), the Prnp ${ }^{Z H 1 / Z H 1}$ mice showed lower values than wild-type mice (session 7: $\mathrm{Prnp}^{+/+}=$ 0.31 vs. Prnp $^{Z H 1 / Z H 1}=-0.02$; session 8: Prnp $^{+/+}=0.54$ vs. Prnp ${ }^{Z H 1 / Z H 1}=0.1$ ), reinforcing the notion that the absence of $\operatorname{PrP}^{\mathrm{C}}$ decreases the instrumental learning goals in mutant mice (Additional file 2: Fig. S2b).

To test for possible deficiencies in motor coordination and balance that could also affect in the results from the Skinner box and the open field tests, we compared the performances of both Prnp ${ }^{+/+}$and Prnp ${ }^{Z H 3 / Z H 3}$ mice in the accelerating rotarod test. After a training session, the mice latency to fall from the rods was tested for five sessions during two consecutive days. In the first day, the $\operatorname{Prnp}{ }^{\mathrm{ZH} 3 / \mathrm{ZH3}}$ mice displayed a significantly lower latency just in the first two session compared to the control mice (Additional file 3: Fig. S3a). However, from the third run, their performance was not significantly different (Session 1: Prnp $^{+/+}=48.51 \pm 3.34$ vs. Prnp ${ }^{\text {ZH3/ZH3 }}=$ $24.48 \pm 7.56, " p=0.014$; Session 2: Prnp $^{+/+}=56.65 \pm$ 6.56 vs. Prnp $^{Z H 3 / Z H 3}=27.30 \pm 8.03$, *** $p=0.007$; Session 3: Prnp $^{+/+}=61.49 \pm 4.69$ vs. Prnp $^{\text {ZH3/ZH3 }}=41.11 \pm 8.20$, $p=0.121$; Session 4: Prnp $^{+/+}=55.71 \pm 2.82$ vs. $\operatorname{Prnp}^{\text {ZH3/ZH3 }}=37.00 \pm 6.45, p=0.189$; Session 5: Prnp $^{+/+}$ $=54.30 \pm 1.73$ vs. Prnp ${ }^{Z H 3 / Z H 3}=38.39 \pm 6.44, p=0.380$; mean \pm S.E.M., two-way ANOVA + Bonferroni's multiple comparisons test). In the second day, no significant difference was observed (Session 1: Prnp $^{+/+}=45.61 \pm$ 5.59 vs. Prnp $^{\text {ZH3/ZH3 }}=31.95 \pm 8.16$; Session 2: Prnp $^{+/+}=$ $53.54 \pm 3.25$ vs. Prnp ${ }^{Z H 3 / Z H 3}=44.99 \pm 7.00$; Session 3: Prnp $^{+/+}=53.67 \pm 4.68$ vs. Prnp ${ }^{Z H 3 / Z H 3}=47.23 \pm 8.03$; Session 4: Prnp $^{+/+}=59.91 \pm 5.48$ vs. Prnp $^{Z H 3 / Z H 3}=$ 
$48.16 \pm$ 9.06; Session 5: Prnp $^{+/+}=52.64 \pm 3.35 \mathrm{vs.}$ $\operatorname{Prnp}^{Z H 3 / Z H 3}=59.01 \pm 9.76$; in all the sessions $p>0.89$, mean \pm S.E.M.; two-way ANOVA + Bonferroni's multiple comparisons test) (Additional file 3: Fig. S3b). These results indicate similar motor capacities in both groups, but Prnp ${ }^{Z H 3 / Z H 3}$ mice needed more trials to reach steady measurements for the same task compared to $\mathrm{Prnp}^{+/+}$mice, suggesting that the knock-out mice have deficits in acquiring instrumental learning as we also observe with the Skinner test (Fig. 2), but not any motor impairment.

Finally, episodic memory was evaluated with the object recognition test (Additional file 4: Fig. S4). In our experiments, most of the Prnp ${ }^{Z H 3 / Z H 3}$ mice interacted with the objects for just a few seconds (Additional file 4: Fig. S4cd). Therefore, we ruled out this approach due to Prnp ${ }^{Z H 3 / Z H 3}$ mouse inactivity, related to the anxiety-like behavior we observed in the open field test. This inactivity led to reduced interactions with the objects that rendered the learning results unreliable. To further support increased anxiety levels in the object recognition test, the fecal bodies left in the arena after the habituation session were counted by the observer once the test subject was removed. Prnp ${ }^{Z H 3 / Z H 3}$ mice exhibited significant increase in fecal bodies present when compared to wildtype mice $\left(\right.$ Prnp $^{Z H 3 / Z H 3}=4.76 \pm 0.56$ vs. Prnp ${ }^{+/+}=1.29$ \pm 0.52. mean \pm S.E.M., ${ }^{* * * *} p<0.001$, Mann-Whitney $U$ non-parametric test) (Additional file 4: Fig. S4b). These results also correlate with the thigmotaxis levels measured in the Prnp ${ }^{Z H 3 / Z H 3}$ mice and indicate that the knock-out mice showed increased emotionality and anxiety compared to their wild-type counterparts. This was in contrast to what was observed using Prnp ${ }^{Z H 1 / Z H 1}$ mice, where the test could be performed. In the habituation session, knock-out mice showed a significant decrease in rearing episodes $\left(\right.$ Prnp $^{+/+}=43.21 \pm 10.01 \mathrm{vs}$. Prnp ${ }^{Z H 1 / Z H 1}=15.7 \pm 2.8$, mean \pm S.E.M., ${ }^{* * *} p<0.001$, Mann-Whitney $U$ non-parametric test) (Additional file 4: Fig. S4e). No changes were observed in the training phase (Additional file 4: Fig. S4f), although the Prnp ${ }^{Z H 1 / Z H 1}$ showed a tendency $(p=0.053)$ to explore the second object less time ((second - first) / total) compared to the wild-type mice $\left(\operatorname{Prnp}^{+/+}=0.3 \pm 0.15 \mathrm{vs}\right.$. $\operatorname{Prnp}^{\mathrm{ZH1} / \mathrm{ZH1}}=-0.17 \pm 0.15$, mean \pm S.E.M.) (Additional file 4: Fig. S4g).

\section{Increased paired-pulse facilitation at high intensities in Prnp ${ }^{\mathrm{ZH} 3 / \mathrm{ZH} 3}$ Schaffer collateral pathway}

$\mathrm{PrP}^{\mathrm{C}}$ has been described as a regulator of glutamatergic neurotransmission in the hippocampus [19, 37]. As an example, $\operatorname{PrP}^{\mathrm{C}}$ has been shown to inhibit NMDAr containing the NR2D subunit [37], or the GluR6/7 receptor [38], see also [57] for review. Therefore, we analyzed the activation of the well-characterized hippocampal
Schaffer collateral pathway (CA3-CA1 synapses). Stimulating and recording electrodes were permanently implanted in the CA3 and CA1 regions, allowing us to record and quantify the evoked fEPSPs in living behaving mice (Fig. 3a). First, we evaluated the putative synaptic facilitation or depression evoked at CA3-CA1 synapses by paired-pulse stimulation of the ipsilateral Schaffer collaterals (Fig. 3b). Paired-pulse stimuli were presented to $\operatorname{Prnp}^{+/+}(n=27)$ and Prnp ${ }^{Z H 3 / Z H 3}(n=24)$ mice at different inter-stimulus intervals (from 10 to $500 \mathrm{~ms}$ ). As already reported for CA3-CA1 synapses [58], this approach generates a higher fEPSP from the second stimulus (fEPSP2) than from the first (fEPSP1) at short intervals due to presynaptic facilitation. In our experiments, as can be observed in the representative examples of fEPSP1 and fEPSP2 (Fig. 3c), no differences were observed between Prnp ${ }^{+/+}$and Prnp ${ }^{Z H 3 / Z H 3}$ facilitation (Fig. 3b), suggesting that $\mathrm{PrP}^{\mathrm{C}}$ does not participate in presynaptic mechanisms related to synaptic facilitation at the least at the selected intensities $(2 \times$ Threshold; $\approx 0.2 \mathrm{~mA}$ ).

Next, we analyzed the consequences of $\operatorname{PrP}^{C}$ deficiency in hippocampal synaptic excitability at a large range of stimulus intensities (Fig. 3d-g). The slope of fEPSP facilitation evoked by paired-pulse $(40 \mathrm{~ms}$ inter-stimulus interval) stimulation was measured at increasing intensities (from 0.02 to $0.4 \mathrm{~mA}$ ). In $\operatorname{Prnp}^{+/+}$mice $(n=14)$, fEPSP1 and fEPSP2 increased steadily more or less in parallel after $0.18 \mathrm{~mA}$ stimulation, reaching asymptotic values at $0.32 \mathrm{~mA}$ (Fig. 3d,e). fESPS2 was significantly greater in three stimulation intensities before arriving at the asymptotic values showing synaptic facilitation $(0.20$ $\mathrm{mA}$ : fESPS1 $=0.35 \pm 0.1 \mathrm{~V} / \mathrm{s}$ and fEPSP2 $=0.88 \pm 0.2 \mathrm{~V} /$ $\mathrm{s}, p=0.124 ; 0.22 \mathrm{~mA}: \mathrm{fESPS} 1=0.50 \pm 0.1 \mathrm{~V} / \mathrm{s}$ and $\mathrm{fEPSP} 2=1.02 \pm 0.2 \mathrm{~V} / \mathrm{s}, p=0.144 ; 0.24 \mathrm{~mA}: \mathrm{fESPS} 1=$ $0.57 \pm 0.1 \mathrm{~V} / \mathrm{s}$ and fEPSP2 $=1.19 \pm 0.2 \mathrm{~V} / \mathrm{s},{ }^{*} p=0.030$; $0.26 \mathrm{~mA}$ : fESPS1 $=0.70 \pm 0.1 \mathrm{~V} / \mathrm{s}$ and $\mathrm{fEPSP} 2=1.32 \pm$ $0.2 \mathrm{~V} / \mathrm{s},{ }^{*} p=0.031 ; 0.28 \mathrm{~mA}: \mathrm{fESPS} 1=0.80 \pm 0.1 \mathrm{~V} / \mathrm{s}$ and $\mathrm{fEPSP} 2=1.42, \pm 0.2 \mathrm{~V} / \mathrm{s}, * p=0.028,0.30 \mathrm{~mA}$ : fESPS1 $=0.92 \pm 0.1 \mathrm{~V} / \mathrm{s}$ and fEPSP2 $=1.47, \pm 0.2 \mathrm{~V} / \mathrm{s}, p$ $=0.111 ; 0.32 \mathrm{~mA}$ : fESPS1 $=0.97 \pm 0.2 \mathrm{~V} / \mathrm{s}$ and $\mathrm{fEPSP} 2=$ $1.50, \pm 0.3 \mathrm{~V} / \mathrm{s}, p=0.192 ; 0.34 \mathrm{~mA}$ : fESPS1 $=1.02 \pm 0.2$ $\mathrm{V} / \mathrm{s}$ and $\mathrm{fEPSP} 2=1.58, \pm 0.3 \mathrm{~V} / \mathrm{s}, p=0.172$; mean \pm S.E.M.; two-way ANOVA + Bonferroni's multiple comparisons test). From $0.26 \mathrm{~mA}$ stimulation, fEPSP1 and fEPSP2 were statistically equal in $\mathrm{Prnp}^{+/+}$mice; thus, there was no synaptic facilitation at high intensities (Fig. $3 \mathrm{~d}, \mathrm{f})$. This phenomenon has been described as a putative protective mechanism in high-intensity insults to maintain hippocampal homeostasis [58]. In contrast, in Prnp ${ }^{Z H 3 / Z H 3}$ mice $(n=15)$, fEPSP1 and fEPSP2 did not increase in parallel, showing an increased facilitation to paired-pulse presentations, and therefore suggesting the absence of this protective mechanism (Fig. 3e,g). fEPSP2 


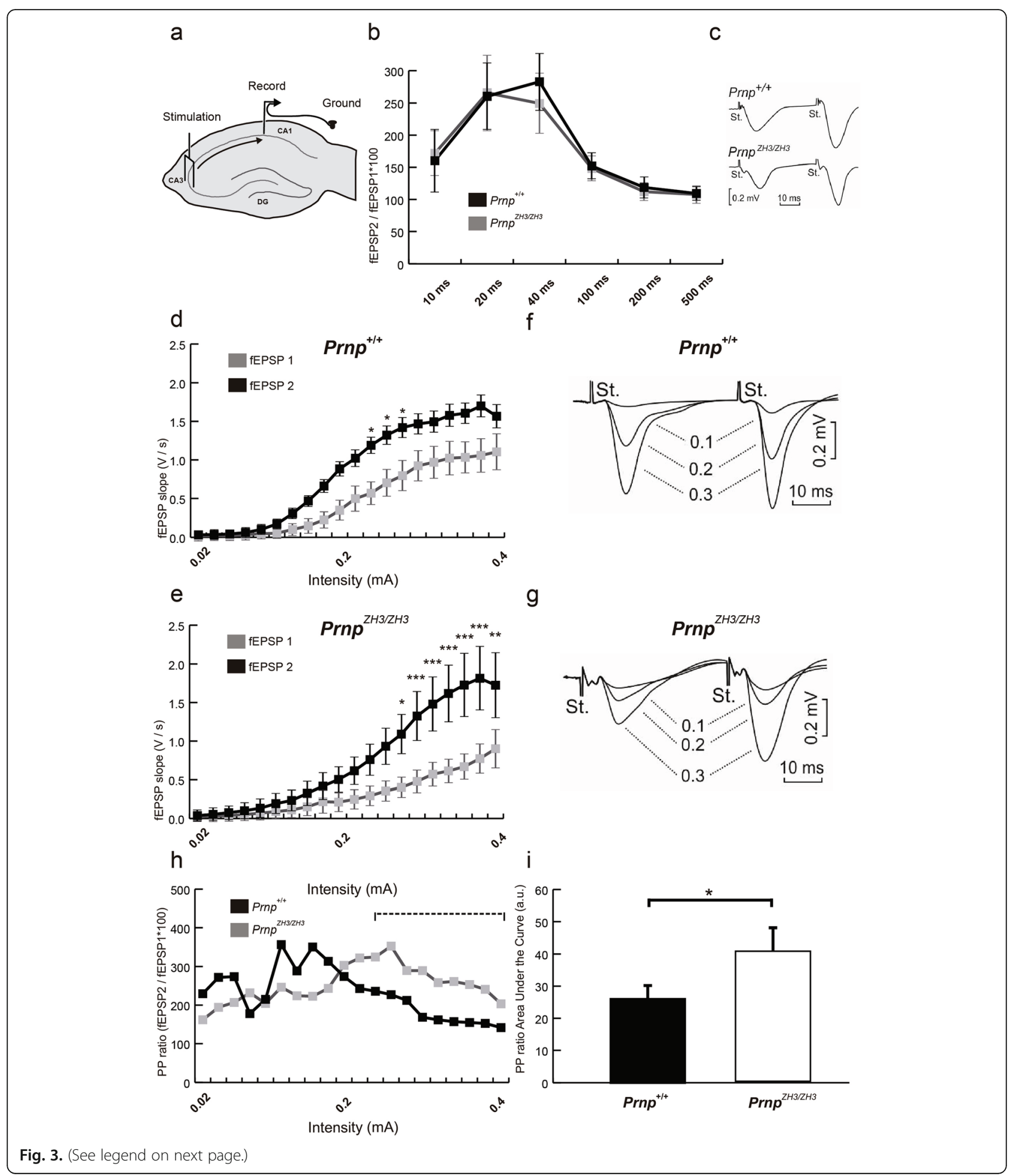


(See figure on previous page.)

Fig. 3. CA3-CA1 synapses in Prnp ${ }^{2 H 3 / 2 H 3}$ mice show enhanced excitability. a Schematic representation of electrodes implanted in mouse dorsal hippocampus. Two stimulation electrodes are implanted in the Schaffer collateral pathway in the CA3 region and two recording electrodes in the CA1 stratum radiatum. b Effects of the paired-pulse stimulation of the Schaffer collateral pathway at increasing inter-stimulus intervals (10, 20, 40, 100, 200, 500 ms). Data are presented as the percentage of increase of fEPSP2 in relation to fEPSP1 (fEPSP2/fEPSP1 $\times 100$ ). c The inset illustrates representative examples of fEPSPs (averaged 5 times) evoked by paired pulses ( $40 \mathrm{~ms}$ of inter-pulse interval) of similar intensities $(2 \times$ Threshold; $\approx$ $0.2 \mathrm{~mA}$ ) in $\mathrm{Prnp}^{+/+}$and Prnp ${ }^{\mathrm{ZH} 3 / \mathrm{ZH} 3}$ mice. d,e Input/output curves of fEPSPs (V/s) in CA1 after the presentation of paired-pulses of increasing intensities in the CA3 area (0.02 mA to $0.4 \mathrm{~mA})$ of $\operatorname{Prnp}^{+/+}$(d) and $\operatorname{Prnp}^{\mathrm{ZH} 3 / \mathrm{ZH} 3}$ (e) mice. $\mathbf{f}, \mathbf{g}$ The insets show representative recordings of fEPSPs evoked in $\operatorname{Prnp}^{+/+}$(f) and $\operatorname{Prnp}^{Z \mathrm{H} 3 / 2 \mathrm{H} 3}$ (g) mice by paired pulses (40 ms of inter-pulse interval) of similar intensities $(0.1 \mathrm{~mA}, 0.2 \mathrm{~mA}$, and $0.3 \mathrm{~mA}$ ). $\mathbf{h}$ Paired-pulse ratio (fEPSP2 / fEPSP1 $\times 100$ ) of data illustrated in $\mathbf{d}$, e, and $\mathbf{i}$ area under the curve (a.u.) of PP ratio from $0.24 \mathrm{~mA}$ to 0.4 intensities. Data are presented as mean \pm S.E.M; $p<0.05,{ }^{* *} p<0.01$, and ${ }^{* * *} p<0.001$, two-way ANOVA + Bonferroni's multiple comparisons test. Source data and individual data values are available in Additional file 10

was significantly greater than fEPSP1 at higher intensities $(0.24 \mathrm{~mA}$ : fESPS1 $=0.293 \pm 0.1 \mathrm{~V} / \mathrm{s}$ and $\mathrm{fEPSP} 2=$ $0.76 \pm 0.1 \mathrm{~V} / \mathrm{s}, p=0.36 ; 0.26 \mathrm{~mA}: \mathrm{fESPS} 1=0.35 \pm 0.1 \mathrm{~V} /$ $\mathrm{s}$ and fEPSP2 $=0.93 \pm 0.2 \mathrm{~V} / \mathrm{s}, p=0.069 ; 0.28 \mathrm{~mA}$ : fESPS1 $=0.4 \pm 0.1 \mathrm{~V} / \mathrm{s}$ and fEPSP2 $=1.09 \pm 0.2 \mathrm{~V} / \mathrm{s},{ }^{*} p=$ 0.010; $0.30 \mathrm{~mA}$ : fESPS1 $=0.48 \pm 0.1 \mathrm{~V} / \mathrm{s}$ and fEPSP2 $=$ $1.33 \pm 0.3 \mathrm{~V} / \mathrm{s}$, ${ }^{* * * *} p=0.0008 ; 0.32 \mathrm{~mA}:$ fESPS1 $=0.57 \pm$ $0.1 \mathrm{~V} / \mathrm{s}$ and fEPSP2 $=1.5 \pm 0.3 \mathrm{~V} / \mathrm{s}$, ${ }^{* * * *} p=0.0002 ; 0.34$ $\mathrm{mA}:$ fESPS1 $=0.61 \pm 0.1 \mathrm{~V} / \mathrm{s}$ and fEPSP2 $=1.62 \pm 0.3 \mathrm{~V} /$ $\mathrm{s},{ }^{* * * *} p<0.0001 ; 0.36 \mathrm{~mA}$ : fESPS1 $=0.67 \pm 0.1 \mathrm{~V} / \mathrm{s}$ and fEPSP2 $=1.73 \pm 0.3 \mathrm{~V} / \mathrm{s}$, ${ }^{* * * *} p<0.0001 ; 0.38 \mathrm{~mA}$ : fESPS1 $=0.77 \pm 0.1 \mathrm{~V} / \mathrm{s}$ and $\mathrm{fEPSP} 2=1.81 \pm 0.4 \mathrm{~V} / \mathrm{s}$, *** $p<$ $0.00010 .40 \mathrm{~mA}$ : fESPS1 $=0.9 \pm 0.2 \mathrm{~V} / \mathrm{s}$ and fEPSP2 $=$ $1.73 \pm 0.4 \mathrm{~V} / \mathrm{s}, * * p=0.004$; mean \pm S.E.M.; two-way ANOVA + Bonferroni's multiple comparisons test). $\mathrm{Prnp}^{+/+}$fEPSP1 increased steadily to greater asymptotic values than Prnp ${ }^{Z H 3 / Z H 3}$ fEPSP1 (from $0.3 \mathrm{~mA}$ stimulation $\approx 50 \%$ increased), but fEPSP2 were almost equal (fEPSP1: Prnp $^{+/+} \approx 1.0 \mathrm{~V} / \mathrm{s} ; \operatorname{Prnp}^{Z H 3 / Z H 3} \approx 0.7 \mathrm{~V} / \mathrm{s}$ and fEPSP2: Prnp $^{+/+} \approx 1.5 \mathrm{~V} / \mathrm{s} ; \operatorname{Prnp}^{Z H 3 / Z H 3} \approx 1.6 \mathrm{~V} / \mathrm{s}$ ). Consequently, the increase in fEPSP1 related to fEPSP2 was $\approx 50 \%$ in Prnp $^{+/+}$individuals, but $>140 \%$ in their Prnp ${ }^{Z H 3 / Z H 3}$ counterparts.

Exacerbation of synaptic facilitation was clearly observed with the paired-pulse (PP) ratio (fEPSP2/ fEPSP1 $\times 100)$. At high intensities, the PP ratio was larger in Prnp ${ }^{\mathrm{ZH} 3 / \mathrm{ZH} 3}$ connections (Fig. 3h). The area under the curve (AUC) from $0.24 \mathrm{~mA}$ intensity was significantly lower in the $\operatorname{Prnp}^{+/+}\left(\right.$Prnp $^{+/+}=26.07 \pm$ 4.0 a.u vs. $\operatorname{Prnp}^{Z H 3 / Z H 3}=40.75 \pm 7.1$ a.u., mean \pm S.E.M., $" p=0.04$; Mann-Whitney $U$ non-parametric test) (Fig. 3i). These results suggest that $\operatorname{PrP}^{C}$ regulates neuronal excitability or, perhaps, synaptic homeostasis at high-intensity stimulations, hinting at a neuroprotective role.

High-frequency stimulation evoked epileptic seizures in Prnp ${ }^{\mathrm{ZH} 3 / \mathrm{ZH} 3}$ Schaffer collaterals but failed to increase LTP

As indicated, several studies reported differing data on LTP in $\operatorname{Prnp}^{0 / 0}$ mice (see "Background"). So, to analyze LTP in Prnp ${ }^{Z H 3 / Z H 3}$ mice, we performed an LTP induction protocol based on high-frequency stimulation (HFS) in 40 mice $\left(\right.$ Prnp $^{+/+}=20$ and Prnp $\left.{ }^{Z H 3 / Z H 3}=20\right)$ (Fig. 4). First, the baseline fEPSPs were recorded for 15 min, evoked by double pulses at an inter-stimulus interval of $40 \mathrm{~ms}$. Afterward, the HFS protocol was presented. This consisted of five trains $(200 \mathrm{~Hz}, 100 \mathrm{~ms})$ of pulses $(1 / \mathrm{s})$ presented six times $(1 / \mathrm{min})$. Recordings were maintained for $60 \mathrm{~min}$ immediately after the HFS and repeated $30 \mathrm{~min}$ daily for 4 days from the HFS presentation session. Prnp ${ }^{+/+}$displayed significant LTP for both pulses (Fig. 4a). fESPS1 and fESPS2 recordings were significantly larger than the baseline after the HFS, and this potentiation lasted for the 5 days of recording sessions (Fig. 4e). As expected, HFS reduced pairedpulsed facilitation on the first day [58]. However, from the second day, facilitation recovered steadily but with a range of increase from 350 to $150 \%$ with respect to fEPSP1 baseline (baseline: fEPSP1 $=100 \%$; fEPSP2 $=$ $268.2 \pm 43.1 \%$; day 1 : fEPSP1 $=478.3 \pm 78.4 \%,{ }^{* * * *} p<$ 0,$001 ;$ fEPSP2 $=441.1 \pm 140.2 \%, " p=0,040$; day 2 : fEPSP1 $=399.9 \pm 65.0 \%,{ }^{* * * *} p<0,001 ;$ fEPSP2 $=554.8 \pm$ $164.2 \%,{ }^{* * * *} p<0,001$; day $3:$ fEPSP1 $=310.4 \pm 47.0 \%,{ }^{* * *} p$ $<0,001$; fEPSP2 $=466.3 \pm 106.7 \%, " p=0,012$; day 4 : fEPSP1 $=279.2 \pm 36.0 \%,{ }^{* * * * *} p<0,001$; fEPSP2 $=438.1 \pm$ 90.7\%, $" p=0,046$; day 5: fEPSP1 $=226.25 \pm 29.4 \%,{ }^{* * *} p=$ 0,0014; fEPSP2 $=433.14 \pm 87.7 \%, p=0,057$; mean \pm S.E.M.; two-way ANOVA + Bonferroni's multiple comparisons test) (Fig. 4a). In contrast, in Prnp ${ }^{Z H 3 / Z H 3}$ mice, LTP induction was virtually absent and paired-pulsed facilitation was maintained $(\approx 60 \%)$ from the first day (e.g., baseline: $\mathrm{EPSP} 1=100 \%$; fEPSP2 $=158.4 \pm 23.0 \%$; day 1 : fEPSP $1=153.43 \pm 15.7 \%$; fEPSP $2=224.3 \pm 39.8 \%$; day 3 : fEPSP1 $=114.2 \pm 11.9 \%$; fEPSP2 $=160.4 \pm 23.8 \%$; in all the sessions $p>0.6$; mean \pm S.E.M.; two-way ANOVA + Bonferroni's multiple comparisons test) (Fig. 4b,f).

In addition, $\operatorname{Prnp}^{+/+}$presented significantly larger fEPSP1 than Prnp ${ }^{Z H 3 / Z H 3}$ mice (day 1: Prnp ${ }^{+/+}=478.3 \pm$ $78.3 \%$ vs. $\operatorname{Prnp}^{Z H 3 / Z H 3}=153.4 \pm 15.7 \%, * * * p<0,001$; day 2: Prnp $^{+/+}=399.90 \pm 65.0 \%$ vs. Prnp ${ }^{\text {ZH3/ZH3 }}=131.77 \pm$ $12.3 \%$, $* * * 0,001$; day $3:$ Prnp $^{+/+}=310.42 \pm 47.0 \%$ vs. $\operatorname{Prnp}^{Z H 3 / Z H 3}=114.22 \pm 11.9 \%,{ }^{* * * *} p=0.0009$; day 4 : 

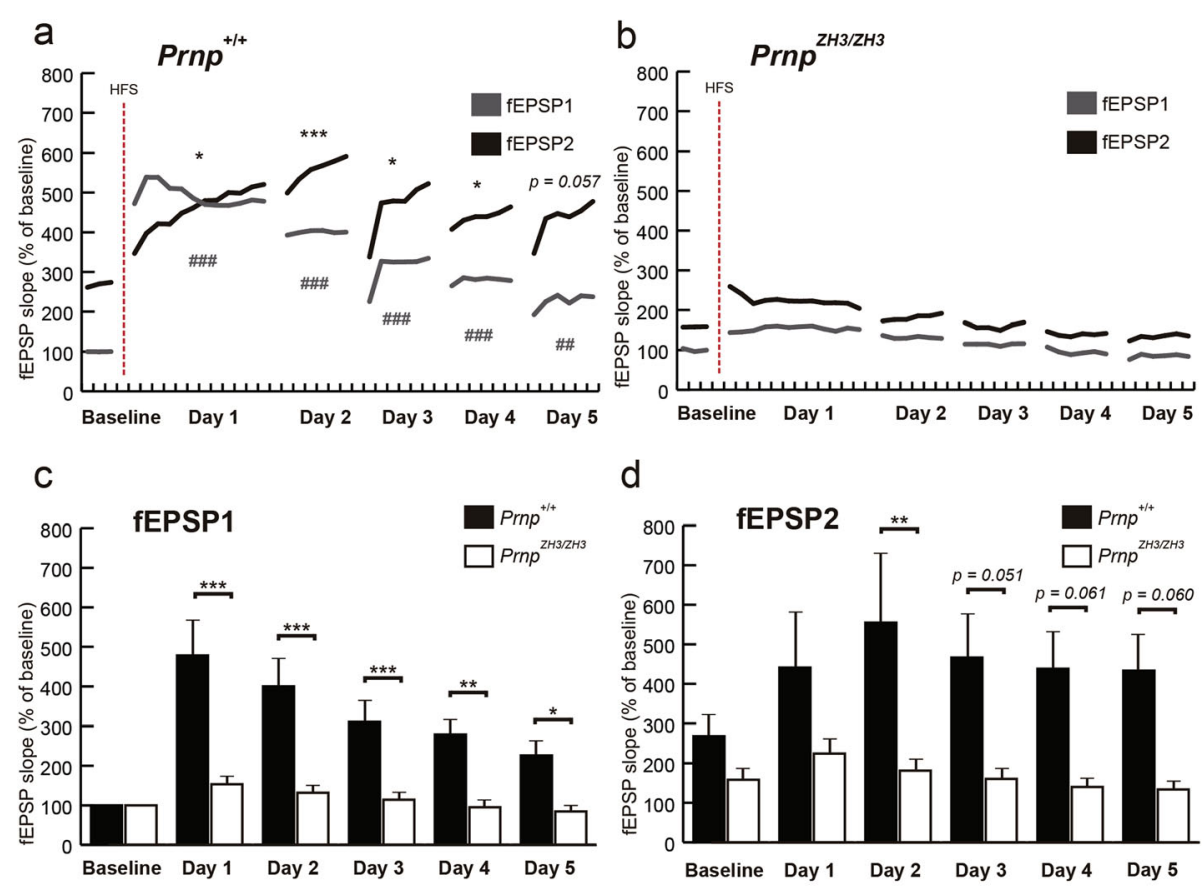

d

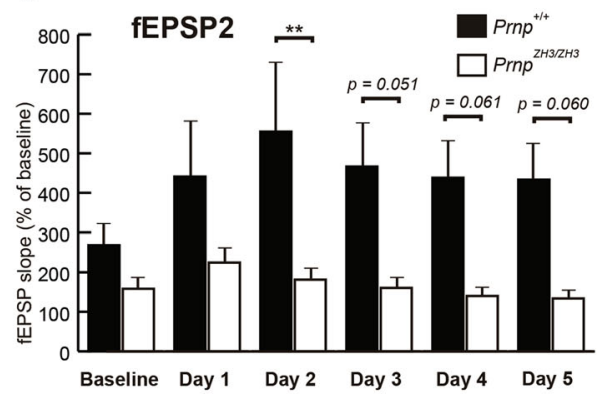

e

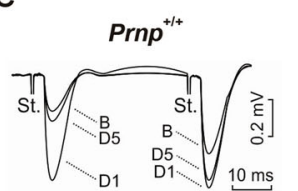

g

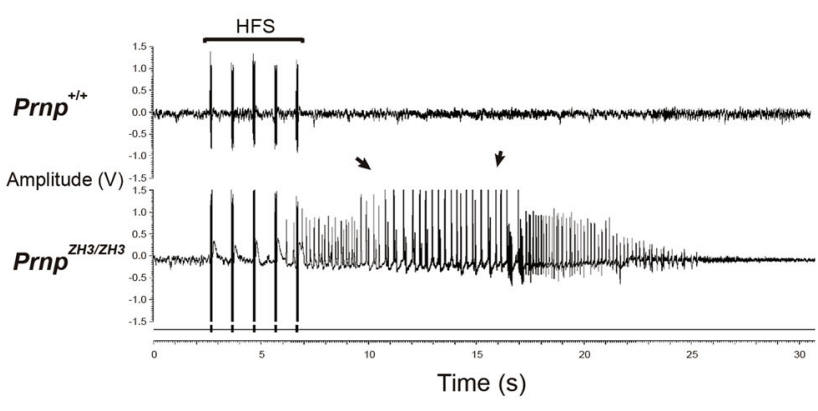

h

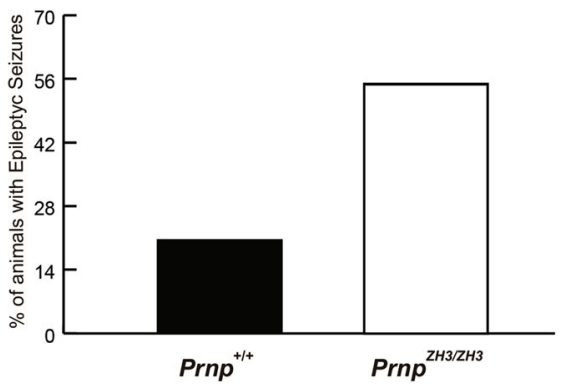

i

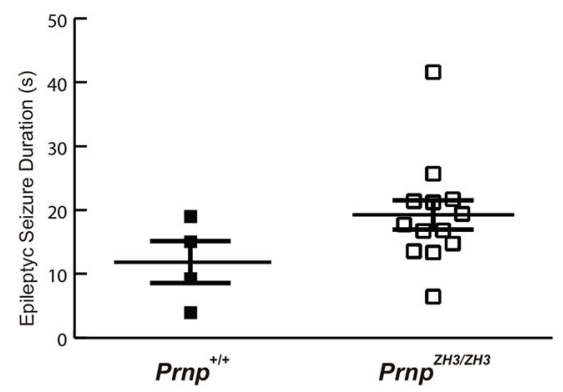

Fig. 4. LTP is not induced at CA3-CA1 synapses of $P r n p^{2 H 3 / 2 H 3}$ mice, and the HFS presentation generates epileptic seizures. a,b Evolution of fEPSP1 evoked in the CA1 region by paired-pulsed stimulation of Schaffer collaterals for the $\operatorname{Prnp}^{+/+}$(a) and $\operatorname{Prnp}^{\mathrm{ZH} 3 / \mathrm{ZH} 3}$ (b) mice after the HFS session. Data are presented as the percentage of increase from baseline. Significant differences with baseline values are presented for fEPSP1 (\#) and fEPSP2 (*) recordings in Prnp ${ }^{+/+}$mice. c,d fEPSP mean slopes from $\operatorname{Prnp}^{+/+}$(c) and $\operatorname{Prnp}^{\mathrm{ZH} 3 / 2 \mathrm{H} 3}$ (d) mice before and after the HFS session. Data are presented as the percentage of increase from baseline values. e,f The insets show representative recordings (averaged 5 times) of fEPSPs evoked in Prnp ${ }^{+/+}$(e) and $\operatorname{Prnp}^{\mathrm{ZH} 3 / \mathrm{ZH} 3}$ (f) mice by paired pulses ( $40 \mathrm{~ms}$ of inter-pulse interval) of similar intensities $(2 \times$ Threshold; $\approx 0.2 \mathrm{~mA})$. g Representative examples of long (30 s) recordings carried out after an HFS stimulation protocol in Prnp ${ }^{+/+}$and Prnp ${ }^{2 \mathrm{H} 3 / \mathrm{ZH} 3}$ Schaffer collaterals. Note the presence of a hippocampal seizure in the Prnp ${ }^{2 \mathrm{H} / \mathrm{ZH} 3}$ mouse (arrows). $\mathbf{h}$ Percentage of mice that presented epileptic seizures following HFS presentations. i Seizure duration (s)

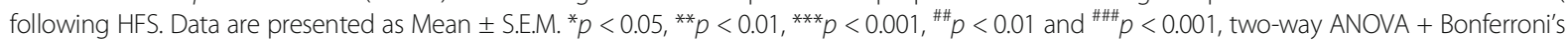
multiple comparisons test and Mann-Whitney $U$ non-parametric test. Source data and individual data values are available in Additional file 10 
Prnp $^{+/+}=279.20 \pm 36.05 \%$ vs. Prnp ${ }^{\text {ZH3/ZH3 }}=95.06 \pm$ 9.26\%, ${ }^{* *} p=0.0021$ day 5: Prnp $^{+/+}=226.3 \pm 29.4 \%$ vs. $\operatorname{Prnp}^{Z H 3 / Z H 3}=84.7 \pm 8.0 \%,{ }^{*} p=0.034$; mean \pm S.E.M.; two-way ANOVA + Bonferroni's multiple comparisons test) (Fig. 4c). Following the same tendency, in Prnp ${ }^{Z H 3 / Z H 3}$ mice, fEPSP2 was also smaller than in Prnp $^{+/+}$(baseline: Prnp $^{+/+}=268.24 \pm 43.1 \%$ vs. Prnp $^{Z H 3 / Z H 3}=158.4 \pm 23.0 \%, p>0.99$; day $1:$ Prnp $^{+/+}=$ $441.1 \pm 140.2 \%$ vs. Prnp ${ }^{Z H 3 / Z H 3}=224.3 \pm 39.8 \%, p=$ 0.370; day 2: Prnp $^{+/+}=554.80 \pm 164.2 \%$ vs. Prnp ${ }^{Z H 3 / Z H 3}$ $=181.4 \pm 25.9 \%$, ${ }^{* * *} p=0.0083$; day $3:$ Prnp $^{+/+}=466.3 \pm$ $106.7 \%$ vs. Prnp $^{\text {ZH3/ZH3 }}=160.39 \pm 23.8 \%, p=0,051$; day 4: Prnp $^{+/+}=438.12 \pm 90.7 \%$ vs. Prnp ${ }^{Z H 3 / Z H 3}=139.73 \pm$ 19.9\%, $p=0,062$; day 5: Prnp $^{+/+}=433.1 \pm 87.7 \%$ vs. $\operatorname{Prnp}^{\text {ZH3/ZH3 }}=133.53 \pm 18.0 \%, p=0.06$; mean \pm S.E.M.; two-way ANOVA + Bonferroni's multiple comparisons test) (Fig. 4d). These results indicate that LTP increased fEPSPs in Prnp ${ }^{+/+}$connections but not in Prnp ${ }^{Z H 3 / Z H 3}$ ones. These results were surprising and were not in accordance with previous publications in which Prnp ${ }^{Z H 1 / Z H 1}$ mice showed even exacerbated LTP [19]. In an attempt to explain these results, we checked the in situ registers in detail during the HFS protocol (Fig. 4g). We observed that $55 \%$ of the Prnp ${ }^{\text {ZH3/ZH3 }}$ mice suffered from epileptic seizures due to HFS in contrast to $20 \%$ of the Prnp ${ }^{+/+}$mice (Fig. 4h). The Prnp ${ }^{Z H 3 / Z H 3}$ epileptic crises tended to be longer (although not statistically significantly) than those suffered by $\operatorname{Prnp}^{+/+}$mice $\left(\right.$Prnp $^{+/+}$ $=12.08 \pm 3.3 \mathrm{~s} ; \operatorname{Prnp}^{\mathrm{ZH} 3 / \mathrm{ZH} 3}=19.55 \pm 2.5 \mathrm{~s}$, mean \pm S.E.M., $p=0.12$; Mann-Whitney $U$ non-parametric test) (Fig. 4i). We postulate that this exacerbated excitability in Prnp ${ }^{Z H 3 / Z H 3}$ synapse impaired a proper LTP generation. The HFS may bring about an aberrant synaptic activation (even generating epileptic seizures) that enables activation of the molecular mechanisms needed for LTP induction. Therefore, as published with chemoconvulsants models [28, 31], $\operatorname{PrP}^{\mathrm{C}}$ might exert protection against electrically induced seizures.

To gain insight into the gene expression patterns altered in the Prnp ${ }^{Z H 3 / Z H 3}$ mice, RNA-seq was performed from the hippocampus region of $8 \mathrm{Prnp}^{+/+}$and 8 $\operatorname{Prnp}^{Z H 3 / Z H 3}$ animals. The sequencing data have been deposited at the Gene Expression Omnibus (GEO) with accession code: GSE189691. (Matamoros-Angles, A; Hervera, A; Soriano, J; Martí, E; Carulla, P, Llorens, F; Nuvolone, M; Aguzzi, A; Ferrer I; Gruart, A; DelgadoGarcía, JM; Del Río, JA. RNA sequencing of hippocampus of Prnp+/+ and PrnpZH3/ZH3 animals. https:// identifiers.org/geo:GSE189691). Around 700 genes showed alterations in their expression profile (323 upregulated and 390 downregulated in Prnp ${ }^{Z H 3 / Z H 3}$ compared to Prnp $^{+/+}$) (Additional files 5 and 6: Table S1 and Table S2). According to pathway analysis in Reactome $\mathrm{v} 77$, the main alterations related to brain functions were the downregulation of genes associated with the "MECP2 regulates neuronal receptors and channels" (10 genes; padj $=1.06 \mathrm{E}-07)$, the "neuronal system" (28 genes; padj. = 0.002), and "protein-protein interaction at synapses" (10 genes; padj. = $8.65 \mathrm{E}-04)$ (Additional file 7: Fig. S5), all in line with the previous behavioral and electrophysiological findings. Among the dysregulated genes, we validated some by RT-qPCR that could explain the phenotype shown by the Prnp ${ }^{Z H 3 / Z H 3}$ mice: including the downregulation of glutamate ionotropic receptor NMDA type subunit 2B (Grin $2 b)$, the GammaAminobutyric Acid Type A Receptor Subunit Rho2 (Gabrr2), the Potassium Voltage-Gated Channels: Subfamily J Member 2 (Kcnj2) and 6 (Kcnj6), Subfamily A Member 1 (Kcna1), and Subfamily Q member 3 (Kcnq3) (Additional file 7: Fig. S5).

\section{Enhanced susceptibility to KA-induced seizures in Prnp ${ }^{\mathrm{ZH} 3 / \mathrm{ZH} 3}$ mice correlates with neuronal death in the hippocampus}

Next, we aimed to explore whether the absence of $\operatorname{PrP}^{\mathrm{C}}$ in the Prnp ${ }^{Z H 3 / Z H 3}$ mice increased their susceptibility to epileptic seizures following KA (i.p.) injections, as reported in Prnp ${ }^{Z H 1 / Z H 1}$ mice (B6129 and B6.129 backgrounds) [28] (Fig. 5). All experiments were carried out on a blind basis, and two different researchers carried out data evaluation (see "Methods" section). Three consecutive injections of $\mathrm{KA}(10 \mathrm{mg} / \mathrm{kg}$ b.w.) were administrated at intervals of $30 \mathrm{~min}$. The epileptic behavior was monitored for $3 \mathrm{~h}$ and was categorized into six stages according to its severity (Fig. 5a). Results indicate that $67 \%$ of $\mathrm{Prnp}^{+/+}$mice did not suffer any severe epileptic episodes (stages I-IV). Only $22 \%$ and $11 \%$ of wild-type mice reached stages $\mathrm{V}$ and VI, respectively. In contrast, 55\% of Prnp ${ }^{Z H 3 / Z H 3}$ mice suffered severe epileptic episodes, $20 \%$ reaching stage $\mathrm{V}$ and $35 \%$ at stage VI (Fig. 5a and Additional file 8: Movie. S1). Moreover, Prnp ${ }^{Z H 3 / Z H 3}$ mice presented more seizures and blinking episodes per animal than Prnp $^{+/+}$individuals (Seizure: Prnp ${ }^{Z H 3 / Z H 3}=$ $2.45 \pm 0.74$ vs. Prnp $^{+/+}=1.06 \pm 0.83 ; p=0.019$; Blinking: $\operatorname{Prnp}^{Z H 3 / Z H 3}=0.95 \pm 0.29$ vs. Prnp $^{+/+}=0.22 \pm 0.13$; mean \pm S.E.M. $p=0.069$; Mann-Whitney $U$ nonparametric test) (Fig. 5b).

Additionally, we evaluated neuronal damage after KAinduced epilepsy with Fluoro-Jade B (Fig. 5c-h). Prnp ${ }^{Z H 3 / Z H 3}$ mice showed relevant numbers of labeled cells in the pyramidal layer of the CA1 and CA3 (Fig. 5c-e), while no signal was observed in Prnp $^{+/+}$sections (Fig. 5f-h). Indeed, CTCF analysis of Fluoro-Jade B labeling in the pyramidal layer of the CA1 and CA3 (see "Methods" section for details) demonstrated statistical differences between $\operatorname{Prnp}^{Z H 3 / Z H 3}$ vs wild-type mice: CTCF value for $P r n p^{Z H 3 / Z H 3}=2893 \pm 349.3$ vs. wildtype $=380 \pm 84.05$; mean \pm S.E.M., ${ }^{* * * *} p<0,001$; Mann- 

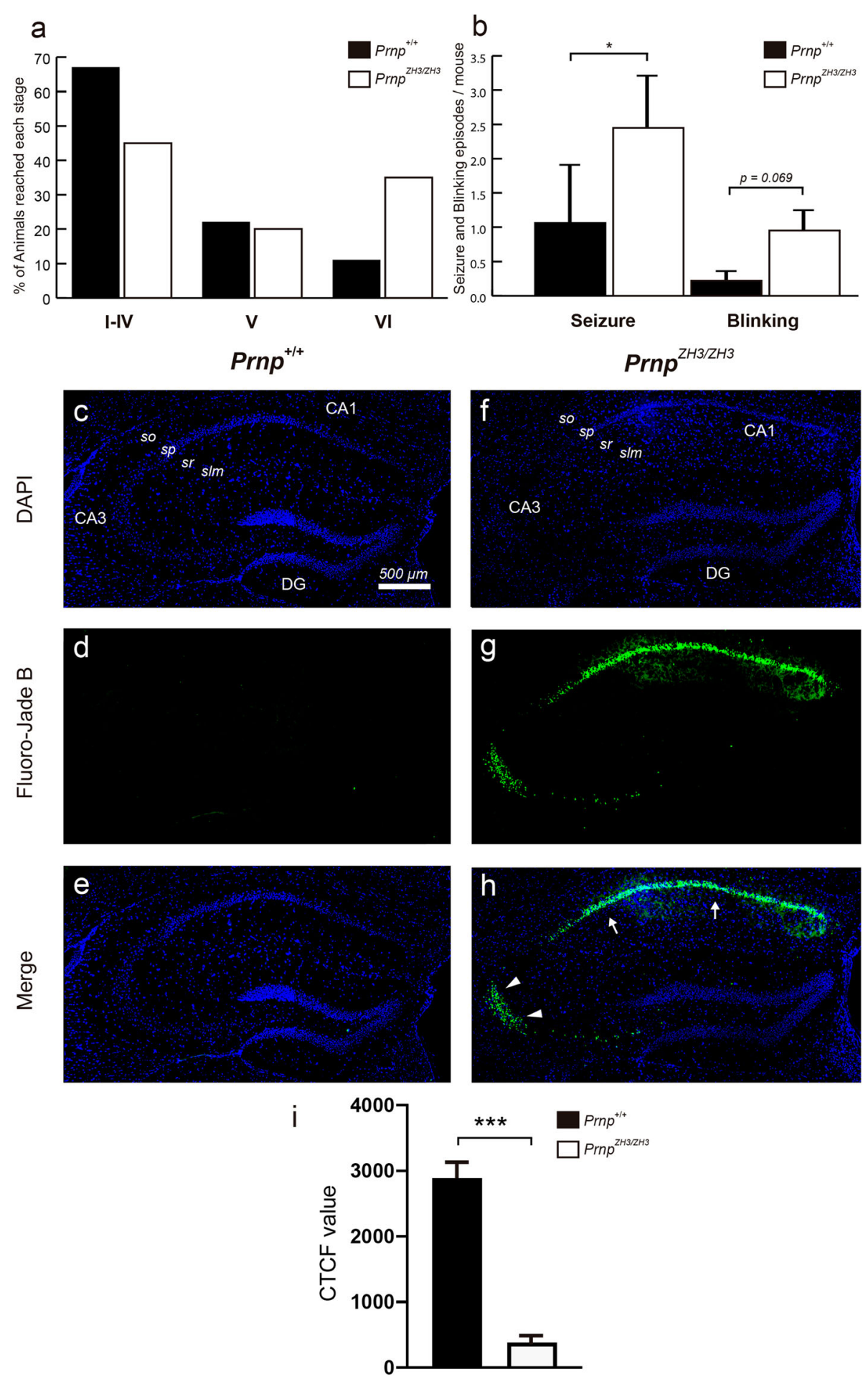

Fig. 5. (See legend on next page.) 
(See figure on previous page.)

Fig. 5. Prnp ${ }^{2 \mathrm{H} / 2 \mathrm{H} 3}$ mice are more susceptible to KA-induced epilepsy correlating with increased neuronal death in CA1 and CA3 pyramidal layers. a Percentage of mice reaching stage I-IV, V, or VI epileptic phenotype after KA administration $(10 \mathrm{mg} / \mathrm{kg})$. $\mathbf{b}$ Number of seizures and blinking episodes presented by $\mathrm{Prnp}^{+/+}$and Prnp ${ }^{\mathrm{ZH} 3 / \mathrm{ZH} 3}$ mice for $3 \mathrm{~h}$ after KA administration. $\mathbf{c}-\mathbf{h}$ Photomicrographs showing the pattern of neurodegeneration with Fluoro-Jade B staining seven days after KA treatment in $\operatorname{Prnp}^{+/+}(\mathbf{c}-\mathbf{e})$ and $\operatorname{Prnp} p^{Z H 3 / Z H 3}$ (f-h) mouse hippocampus. Nuclei are stained with DAPI (c, f). Dying cells $(\mathbf{d}, \mathbf{g}$, stained with Fluoro-Jade B) are located in the pyramidal cell layer of CA1 (arrows) and CA3 (arrowheads) areas. $\mathbf{i}$ Graph illustrating the analysis of the CTCF values in the CA1-3 pyramidal layer of Prnp ${ }^{2 H 3 / Z H 3}$ and wild-type mice (see "Methods" for details). Data are presented as a percentage in a and as mean \pm S.E.M, in $\mathbf{b}$ and $\mathbf{i} ;{ }^{*} p<0.05$ and ${ }^{* * *} p<0.001$, Mann-Whitney $U$ non-parametric test. Abbreviations: so, stratum oriens; sp, stratum pyramidale; sr, stratum radiatum; slm, stratum lacunosum-moleculare; DG, dentate gyrus. The scale bar in $\mathbf{c}$ is also representative for $\mathbf{d}-\mathbf{h}$. Source data and individual data values are available in Additional file 10

a

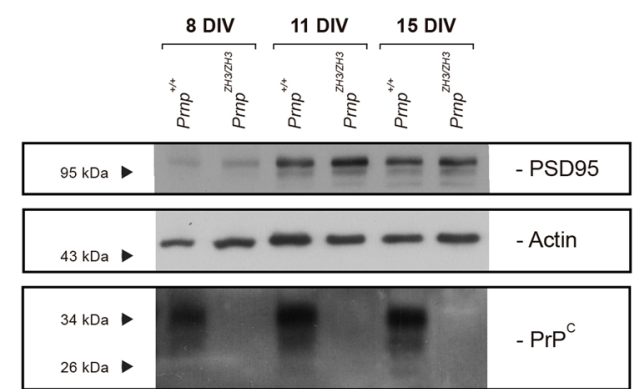

b
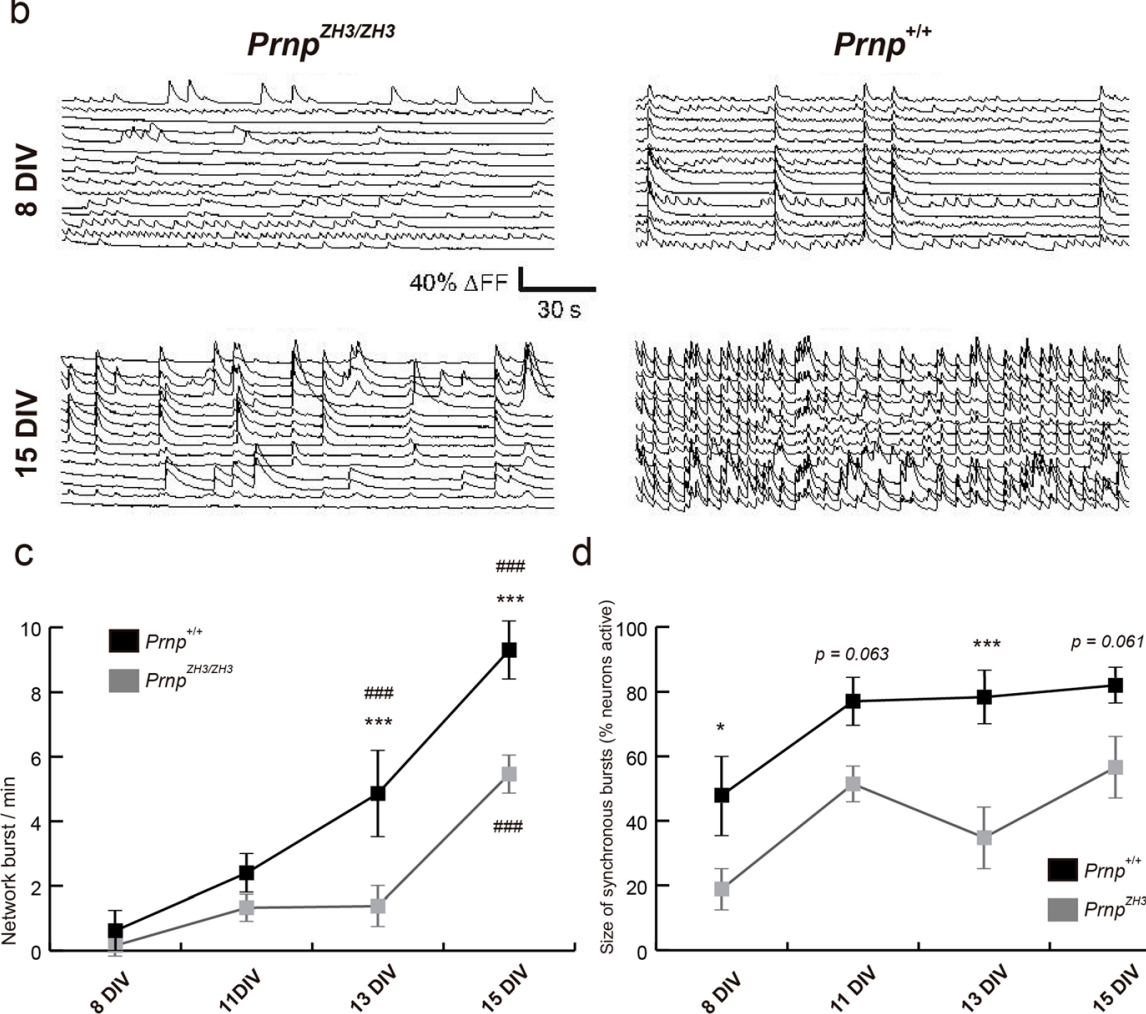

d

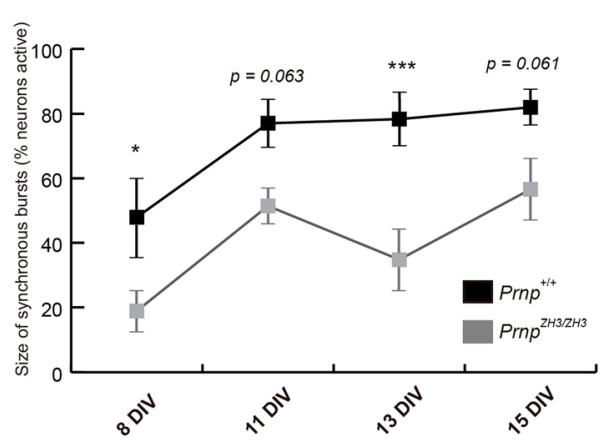

Fig. 6. Reduced bursting and network formation in neuronal Prnp ${ }^{2 H 3 / 2 H 3}$-derived cultures. a Immunoblot analysis of PrPC expression and PSD95 in

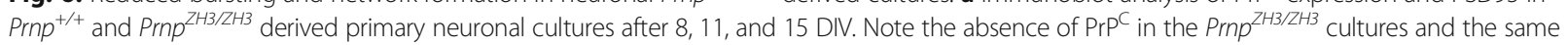
PSD95 expression in each DIV. Actin is used as a loading control. b Representative examples of neuronal traces at 8 and 15 DIV in the Prnp ${ }^{+/+}$and

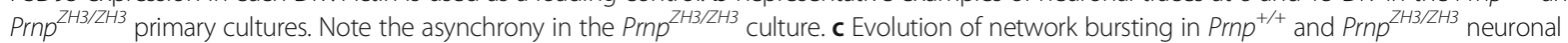
cultures from 8 to 15 DIV. Data are presented as the mean of bursts/min \pm S.E.M. d Evolution of size of synchronous bursts from 8 to 15 DIV. Data are presented as the mean percentage of active neurons \pm S.E.M. Asterisks (*) indicate significant differences between Prnp ${ }^{+/+}$and Prnp ${ }^{Z H 3 / 2 H 3}$ bursting. Number sign (\#) indicates significant differences with the respective baseline bursting at 8 DIV. ${ }^{*} p<0.05,{ }^{* * *} p<0.001$ and ${ }^{\# \# \#} p<0.001$, two-way ANOVA + Bonferroni's multiple comparisons test. Source data and individual data values are available in Additional file 10 
Whitney $U$ non-parametric test (Fig. 5i). These results corroborated the absence of Prnp to generate an exacerbated synaptic excitability in the hippocampal region that increases susceptibility to electrical and KA-induced seizures, causing neuronal death in the CA1 and CA3 regions of the pyramidal layer of the hippocampus proper.

\section{Neuronal Prnp ${ }^{\mathrm{ZH} 3 / \mathrm{ZH} 3}$-derived cultures show reduced bursting and impairment network formation in vitro} $\operatorname{PrP}^{\mathrm{C}}$ has also been described as a regulator of neurogenesis and neuronal differentiation in vitro and in vivo (see [6-8] for reviews). Furthermore, defects in neuronal network connectivity and maturation are related to epilepsy [59]. Consequently, we tested whether $\operatorname{Prnp}{ }^{Z H 3 / Z H 3}$ increased excitability might be due to changes in the neuronal differentiation inducing aberrant connectivity and an immature neuronal network. To analyze this, calcium imaging was performed in primary cortical cultures $(n=$ 10 in both genotypes) from Prnp $^{+/+}$and Prnp ${ }^{Z H 3 / Z H 3}$ mouse embryos (E16.5-E17.5) expressing the GECI indicator GCaMP6f under the neuronal syntaxin promoter [60], allowing us to record calcium traces of the same neuronal population after $8,11,13$, and 15 days in vitro (DIV) (Fig. 6).

Prnp $^{+/+}$and Prnp ${ }^{\mathrm{ZH} 3 / \mathrm{ZH} 3}$ cultures displayed the same number of collective bursts/min at 8 and 11 DIV (Fig. 6c). After that, a delay in Prnp ${ }^{Z H 3 / Z H 3}$ neuron activity was observed compared to controls. Prnp ${ }^{+/+}$cultures increased the number of bursts/min significantly at 13 DIV; however, Prnp ${ }^{\mathrm{ZH} 3 / \mathrm{ZH} 3}$ cultures needed two additional days, at 15 DIV (Fig. 6b,c). Moreover, Prnp ${ }^{+/+}$ neurons exhibited significantly more bursts/min at 13 DIV and 15 DIV than Prnp ${ }^{Z H 3 / Z H 3}$ ones and overall the latter showed a reduced firing interval along development (8 Div: Prnp ${ }^{+/+}=0.62 \pm 0.4$ vs. Prnp ${ }^{\text {ZH3/ZH3 }}=0.16$ \pm 0.1 bursts $/ \mathrm{min} ; 13$ Div: Prnp $^{+/+}=4.86 \pm 1.1$ vs. Prnp ${ }^{Z H 3 / Z H 3}=1.38 \pm 0.4 ;{ }^{* * * *} p<0.001 ; 15$ Div: Prnp $^{+/+}=$ $9.30 \pm 0.7$ vs. Prnp ${ }^{Z H 3 / Z H 3}=5.46 \pm 0.4$; mean \pm S.E.M. *** $p<0.001$; ANOVA + Bonferroni's multiple comparisons test) (Fig. 6c). The Prnp ${ }^{Z H 3 / Z H 3}$ cultures also showed a reduction in the size of synchronous bursts. In the $\operatorname{Prnp}^{+/+}$cultures, around $80 \%$ of the neurons showed synchronic activity at 11,13, and 15 DIV, while this value was around 50\% in Prnp ${ }^{Z H 3 / Z H 3}$ cultures (Fig. 6d). These results demonstrate that collective bursting is reduced and delayed in $\operatorname{Prnp}{ }^{Z H 3 / Z H 3}$ cultures, suggesting that Prnp expression is necessary for network formation and maturation.

\section{Discussion}

$\mathrm{PrP}^{\mathrm{C}}$ has been associated with several physiological functions using in vivo approaches; however, the consequences of $\operatorname{PrP}^{C}$ deletion in behavior and cognition have not been extensively evaluated [9]. There are some studies about $\operatorname{Prnp}^{0 / 0}$ mouse behavior, motor capabilities, and learning performance, but the results are not conclusive, especially after the description of the so-called FG in the background of the Prnp ${ }^{Z H 1 / Z H 1}$ model that masks specific $\operatorname{PrP}^{\mathrm{C}}$ roles [26]. For example, concerning KA susceptibility, a clear decrease is observed in mice expressing a lower percentage of $129 / \mathrm{Sv}$-associated polymorphisms (B6.129) compared to the B6129 original strain of the Prnp ${ }^{Z H 1 / Z H 1}$ mice with a higher percentage of $129 / \mathrm{Sv}$ genome [28]. Here we assess the consequences of the absence of $\operatorname{PrP}^{C}$ in behavior and neurotransmission using the new strictly co-isogenic mouse model Prnp ${ }^{Z H 3 / Z H 3}$ [50]. However, another relevant aspect of these studies is the age of the analyzed mice, since physiological differences in the absence of Prnp have been described in association with age for $\operatorname{Prnp}^{Z H 1 / Z H 1}$ [45] or FVB/N$\operatorname{Prnp}^{Z H 1 / Z H 1}$ [61]. Thus, in our study, we only used and compared results obtained from mice of 3-5 months of age. Concerning nest-building behavior, our results suggest similar behavior in $\operatorname{Prnp}^{\mathrm{ZH} 3 / \mathrm{ZH} 3}$ and wild-type mice. This contrasts with previously reported results [42], but it has been largely demonstrated that this capacity is dependent on mouse background [62,63].

Our results also reveal that $\operatorname{Prnp}{ }^{Z H 3 / Z H 3}$ mice display reduced activity in the open field test. The reduced rearing exploration and peripheral preference in the arena, and the high defecation rate observed in $\operatorname{Prnp}^{Z H 3 / Z H 3}$ mice, suggest an anxiety-like behavior. Indeed, $\operatorname{Prnp}{ }^{Z H 3 / Z H 3}$ showed higher thigmotaxis than wild-type mice (see [64] for technical details). Our data correlate with those reported by Schmitz et al. [45] and Lobao-Soares et al., both using 3-month-old Prnp ${ }^{Z H 1 / Z H 1}$ mice, illustrating reduced mobility between the inner and outer regions of the open field and increased defecation in Prnp ${ }^{\mathrm{ZH1} / \mathrm{ZHI}}$ mice [65]. However, they are in contrast to Nico et al. [66], where they found no differences, and with Gadotti et al. [52], that showed 10-week-old Prnp ${ }^{Z H 1 / Z H 1}$ mice displayed increased crossing in open-field test although thigmotaxis changes were not analyzed in the study. Although technical details could also play a role (i.e., handling of the mice, the initial position of the mice in the field, geometry of the field), we think that these discrepancies reinforce the relevance of the homogenous genetic background in our study vs. the others. In fact, the differences we observed also extend to the rotarod test. Our results showed no motor alternations in the $\operatorname{Prnp}{ }^{\mathrm{ZH} 3 / \mathrm{ZH} 3}$ mice, but they need more sessions to learn the task compared to controls. Previous publications also showed any motor alterations in two different knock-out strains [45, 65, 
67]. However, Nazor et al. observed changes just in mice older than 95 days [61].

In our experiments, $\operatorname{Prnp}^{Z \text { ZH/ZH3 }}$ mice also failed to achieve instrumental learning in the Skinner box. These results are similar to those observed in $\operatorname{Prnp}{ }^{Z H 1 / Z H 1}$ mice (B6.129 background, 2-5\% 129/Sv markers, [28]). Striking differences in motility between wild-type and knockout mice were identified using this approach. However, learning capacity based on the ON/OFF paradigm confirmed the operant conditioning deficiencies, a type of associative learning.

Following our results, alterations in locomotor activity and increased latency to initiate exploration were previously reported in other Prnp ${ }^{0 / 0}$ mouse models [42, 47]. Anxiety-related behavior [54], depressive tendencies [52], and alterations in spatial memory and learning have also been described [42, 45]. In contrast, Bueler et al. reported no alterations in Prnp ${ }^{Z H 1 / Z H 1}$ behavior [24]. This disparity in results might be explained by the age of the animals used in the studies. Bueler and collaborators performed the test with 2- and 3-month-old mice, which could potentially uncover the behavior impairment as it was reported to be an age-dependent decline in other publications using the Prnp ${ }^{Z H 1 / Z H 1}$ model $[45,68]$. Another study also showed no deficits in $\operatorname{Prnp}{ }^{0 / 0}$ mouse behavior, where Prnp was conditionally deleted at 12 or 16 months, and the results included no alterations in the Morris water maze or object recognition test [53]. We reported behavioral deficits in Prnp ${ }^{0 / 0}$ mouse models with some discrepancies with the previous works, most likely related to age-related sampling and the mice's background.

Glutamate neurotransmission is, in large part, responsible for cortical signaling, and its impairment has been related to behavioral deficits [69]. $\operatorname{PrP}^{\mathrm{C}}$ has been described as a regulator of glutamate synapses [13]. Even glutamate inhibition with an NMDA antagonist (MK801) ameliorates depressive-like behavior in $\operatorname{Prnp}^{0 / 0}$ mice [52]. Thus, our next step was to study glutamate connectivity to better understand behavioral alterations. The hippocampal Schaffer collaterals and their implication in operant conditioning, spatial learning, and anxietyrelated behavior were evaluated as a well-defined model of glutamate circuitry [70].

The paired-pulse facilitation test did not show differences between Prnp ${ }^{Z H 3 / Z H 3}$ and Prnp ${ }^{+/+}$animals. Therefore, $\operatorname{PrP}^{\mathrm{C}}$ deletion did not alter synaptic facilitation, at least in the living behaving mouse model, at the least at relatively low stimulation intensities (Fig. 3b). These results may be explained by the fact that synaptic facilitation is mainly a presynaptic phenomenon [71], and $\operatorname{PrP}^{\mathrm{C}}$ has been related to postsynaptic neurotransmission mechanisms $[37,38]$. These differences in pre- and postsynaptic mechanisms would explain the different results collected from Prnp ${ }^{Z H 3 / Z H 3}$ mice and their littermate controls in paired-pulse ratio and LTP tests.

Nevertheless, Prnp ${ }^{Z H 3 / Z H 3}$ mice displayed increased synaptic facilitation at high intensities, a fact not observed in controls. This could represent a sort of compensatory phenomenon for their evident LTP deficits. In addition, Prnp ${ }^{Z H 3 / Z H 3}$ mice presented an increased susceptibility to KA-induced seizures. This epileptogenic phenotype may explain our results on anxiety behavior in Prnp ${ }^{\mathrm{ZH} 3 / \mathrm{ZH3}}$ mice. Comorbid anxiety disorders affect patients with epilepsy [72], and cognitive decline has been described in epileptic animal models [73]. Moreover, increased excitability was previously reported, especially in susceptibility to KA, NMDA, and pentylenetetrazol (PTZ) insults [30, 31].

However, contradictory results were published by other groups, who described an elevated epileptic threshold in $\operatorname{Prnp}^{O / O}$ hippocampal slices treated with bicuculline, zero-magnesium conditions, and PTZ [74], and also normal neurotransmission-associated parameters compared with wild-type mice [25]. Both studies recorded hippocampal slices of the FVB/N-Prnp ${ }^{0 / 0}$ model, a mouse with a triple mixture background (FVB/129Sv/ C57BL6) which carried the FG [26]. Different susceptibility to KA-induced seizures among mice with different backgrounds has been described; even the FVB background has been shown as highly susceptible to epilepsy $[75,76]$. Our results using Prnp ${ }^{Z H 3 / Z H 3}$ animals in KA susceptibility were similar to those previously obtained with the other available $\operatorname{Prnp}^{0 / 0}$ co-isogenic mouse model, the Edinburgh 129/Ola [28]. Therefore, we postulate that these contradictory results published about the excitability of $P r n p^{O / O}$ synapse are likely associated with the mouse backgrounds, the FG effect, and the experimental approach. However, the ZH3 mice results demonstrate that $\operatorname{PrP}^{C}$ indeed protects against KAinduced epilepsy.

Our results show that the presentation of HFS protocols causes epileptic seizures in most Prnp ${ }^{Z H 3 / Z H 3}$ mice but fails to generate significant LTP at the hippocampus. Some controversial results have been published about the implication of $\operatorname{PrP}^{C}$ in LTP generation. Different experimental approaches (hippocampal slices or in vivo experiments) and a mixture of mouse models with distinct backgrounds were used, generating non-comparable data (i.e., [19, 25, 40, 42]). Here, using ZH3 mice, we hypothesize that the absence of $\operatorname{PrP}^{\mathrm{C}}$ ends in LTP induction failure due to exacerbated synaptic excitability, although we cannot rule out putative GABAergic disinhibition. It is convincingly demonstrated that severe epileptic seizures cause neuronal death, which hampers LTP generation. Moreover, non-severe epileptic seizures generate similar molecular and synaptic changes to LTP $[77,78]$. This suggests that non-severe HFS-induced 
seizures somehow saturate the postsynaptic terminal, over-activating LTP-induction mechanisms that reduce LTP production capacity by HFS. Additionally, $\operatorname{PrP}^{\mathrm{C}}$ has also been described as interacting with key elements required for LTP-related mechanisms AMPA or NMDA receptors [37, 39, 79, 80], see also [57] for review.

The presented data show that Prnp ${ }^{0 / 0}$ hippocampal synapse is highly excitable and epileptogenic. Alterations in brain connectivity due to developmental alterations, traumas, or infections contribute to this neuromodulation imbalance [59]. In order to assess whether the epileptic phenotype displayed by $\operatorname{Prnp}{ }^{Z H 3 / Z H 3}$ animals came from neuronal connectivity alterations, we studied bursting and network formation in $\operatorname{Prnp}{ }^{Z H 3 / Z H 3}$-derived primary neuronal cultures. Relevant $\operatorname{PrP}^{\mathrm{C}}$ expression in vitro is observed from 4 to 5 DIV [81]. Our results indicate that Prnp ${ }^{Z H 3 / Z H 3}$ cultures did not mature or connect properly; they displayed asynchronous and very low bursting compared to wild-type cultures. These results suggest that the absence of $\operatorname{PrP}^{\mathrm{C}}$ causes a delay in neuronal maturation, but more relevantly in neural network formation and function. In fact, the role of $\operatorname{PrP}^{\mathrm{C}}$-mediated signals in neuritogenesis has been demonstrated [82-84]. However, to our knowledge, this is the first description of network alterations due to the absence of $\operatorname{PrP}^{\mathrm{C}}$. However, and as indicated by Benvegnu and coworkers [85], there are gene expression changes during the development of FVB/N Prnp ${ }^{0 / 0}$ and wild-type hippocampus. Hence, changes in ion conductance or channel receptor expression might be involved in this delay. In this line, electrophysiological experiments with biochemical characterization might confirm the basis of the delay in maturation in vitro.

Finally, the gene ontology analysis of the RNAseq of Prnp ${ }^{Z H 3 / Z H 3}$ and Prnp ${ }^{+/+}$mouse hippocampus showed downregulation of genes associated with the neuronal system and protein-protein interaction at synapses, fitting the phenotype we observed in the knock-out mice. The significant downregulation of Gabrr2 and Grin $2 b$ in Prnp ${ }^{Z H 3 / Z H 3}$ mice would produce dysregulation in the excitatory/inhibitory balance, increasing the excitability of the system, as we describe with the KA and the HFS analyses. The alteration of the inhibitory neurotransmission was already shown in Prnp $^{0 / O}$ models since they were susceptible to suffering from epileptic crises (see references above). $\operatorname{PrP}^{\mathrm{C}}$ has been widely described as a regulator of glutamatergic neurotransmission and its receptors, as we show here with the Grin2b. Moreover, mutations at Grin $2 b$ have recently been related to a rare brain disease, the GRIN2B-related neurodevelopmental disorder that causes intellectual disability, autismspectrum-like behavior, epilepsy, and, sometimes, locomotor deficiencies as well $[86,87]$. Therefore, the altered expression of Grin $2 b$ might contribute to the behavior and learning deficits observed in the Prnp ${ }^{Z H 3 / Z H 3}$ mice.

\section{Conclusions}

In conclusion, our study points that the absence of $\operatorname{PrP}^{\mathrm{C}}$ impairs neuronal network formation and connectivity, producing enhanced susceptibility to excitotoxicity insults such as HFS and KA exposure. This epileptogenic circuitry seems to impair highly cognitive-demanding functions such as associative learning, and it produces anxiety-like behavior.

\section{Methods}

\section{Animals}

Adult C57BL/6 J mice $\left(\mathrm{Prnp}^{+/+}\right)$were purchased from Charles River Laboratories (Paris, France). Prnp ${ }^{Z H 3 / Z H 3}$ mice line was provided by A. Aguzzi (Switzerland) (see [50] for details). Prnp ${ }^{\mathrm{ZHI} / \mathrm{ZH1}}$ mice [24] were purchased from the European Mouse Mutant Archive (EMMA, Monterotondo, Italy). A total of 185 adult (3-5 months old) male mice (ZH3: Prnp $^{+/+}=81$ and Prnp ${ }^{\text {ZH3/ZH3 }}=$ 84; ZH1: Prnp $^{+/+}=10$ and Prnp ${ }^{Z H 1 / Z H 1}=10$ ) were used in the present study. In ZH1 mouse experiments, null Prnp ${ }^{Z H 1 / Z H 1}$ and control mice $\left(\right.$ Prnp $\left.^{+/+}\right)$were obtained by crossing heterozygous Prnp ${ }^{+/ Z H 1}$ mice to obtain a mixed background (B6.129). It is well described that behavior and neural physiology are different between male and female rodent models due to several hormone and non-hormone-derived reasons [88]. Thus, we used only males in order to establish an equivalent group comparable with previous publications. All experiments were performed following the protocols and guidelines of the Ethical Committee for Animal Experimentation (CEEA) of the University of Barcelona. CEEA of the University of Barcelona approved the protocol for using animals in this study (CEEA approval \#276/16 and 141/15). Behavioral and electrophysiological studies were performed following the guidelines of the European Union Council (2010/276:33-79/EU) and current Spanish regulations (BOE 34:11370-421, 2013) for the use of laboratory animals in chronic experiments. Experiments were also approved by the Ethics Committee for Animal Care and Handling of the Pablo de Olavide University (UPO-JA 06/03/2018/025).

\section{Immunoblotting}

Proteins from brain tissue lysates or primary cortical neurons were extracted using RIPA buffer with protease and phosphatase inhibitor cocktails (Roche). Total lysates were obtained by $30 \mathrm{~s}$ of centrifugation at $4{ }^{\circ} \mathrm{C}$. The protein concentration of the lysates was quantified using Pierce BCA Protein Assay Kit (Thermo Scientific). Then, $10-50 \mu \mathrm{g}$ of proteins were loaded to SDS-PAGE gels and 
transferred and transferred to nitrocellulose membranes for $1 \mathrm{~h}$. Membranes were blocked with Tris-buffered solution with $0.1 \%$ tween, $5 \%$ skimmed milk, and $2 \%$ of FBS for $1 \mathrm{~h}$ at room temperature (RT) and incubated with PSD95 (1:1.000, MAB1598; Millipore), PrP (1:500; 6H4; Thermo) or Actin (1:20.000; MAB1501; Millipore) antibodies at $4{ }^{\circ} \mathrm{C} \mathrm{O} / \mathrm{N}$. Following HRP-linked secondary antibody (Dako) incubation for $1 \mathrm{~h}$ at $\mathrm{RT}$, membranes were developed with ECL substrate (Thermo).

\section{Behavioral studies}

A total of 147 animals were used in these sets of experiments (ZH3: Prnp $^{+/+}=63$ and Prnp ${ }^{Z H 3 / Z H 3}=64 ; \mathrm{ZH} 1$ : Prnp $^{+/+}=10$ and Prnp $\left.{ }^{Z H 1 / Z H 1}=10\right)$. Mice were housed alone in boxes on a 12/12 h light/dark cycle with constant ambient temperature $\left(21 \pm 1^{\circ} \mathrm{C}\right)$. Water and food were provided ad libitum except for the instrumental learning tests (see below).

\section{Nest building}

For this test, a total of 14 mice ( 3 months old) were used $\left(\operatorname{Prnp}^{Z H 3 / Z H 3}=7\right.$ and $\left.\operatorname{Prnp}^{+/+}=7\right)$. On the first day of testing, one piece of tissue paper $(36 \times 12 \mathrm{~cm})$ was placed in the cage to facilitate nest building (Additional file 1: Fig. S1). The presence and the quality of each nest were photo-documented and evaluated the following day according to a modified 5-point scale using the method described by Deacon [89]. Two different blinded researchers evaluated the nest generated by each mouse. Data are presented as the mean \pm S.E.M. in (Additional file 1: Fig. S1). The statistical analysis was performed with the Mann-Whitney non-parametric test (GraphPad Prism 8 software).

\section{Open field test}

In this test, $\operatorname{Prnp}{ }^{Z H 1 / Z H 1}$ mice were not used since detailed studies were already developed using this model $[45,54]$. In our experiments, mice $\left(\right.$ Prnp $^{+/+}=49$ and Prnp $\left.{ }^{\mathrm{ZH3} / \mathrm{ZH} 3}=49\right)$ were placed in a square open field altimeter box $(35 \times 35 \times 25 \mathrm{~cm}$, Cibertec, Madrid, Spain $)$. The field had a grid $(16 \times 16 \mathrm{~cm})$ of infrared lasers on the $X Y$-axis and one on the $Z$-axis. Locomotor activity was measured for $15 \mathrm{~min}$ in mice with the MUXXYZ16L software. Mice were placed in the box's periphery for $15 \mathrm{~min}$ for two consecutive days, and their behavior was recorded. The first day was considered a training session to reduce mouse anxiety associated with manual handling, and the data analyzed and displayed in the manuscript corresponded to the second session. The system inferred mouse activity by counting laser intersections. For anxiety-related behavior measurement, the center (inner) square of the field $(10 \times 10 \mathrm{~cm})$ was considered as the central zone and the rest of the square as the peripheral (outer) zone [56] (see Fig. 1a). For quantification and to distinguish motility from exploratory behavior, it was considered that a mouse spent time in one of the regions (center vs. periphery) if it remained in the region at least $3 \mathrm{~s}$. Rearing episodes were considered when the animal stood up for at least $3 \mathrm{~s}$, and immobility episodes if immobile for an additional $3 \mathrm{~s}$. Obtained data were analyzed, and the sum of the crossed $X$ - and the $Y$-axes are presented together to show total mouse mobility in the experiments. The time spent in the maze periphery zones measures thigmotaxis or wallhugging behavior and indicates anxiety-related behavior [56]. Data are presented as the mean \pm S.E.M. The statistical analysis was performed with a $T$-test or Mann-Whitney $U$ non-parametric test (GraphPad Prism 8 software). The asterisks indicate significant differences: *** $p<0.01$ and $* * * 0<0.001$. The arena and the walls were cleaned with soap and ethanol between trials to remove olfactory cues between experiments.

\section{Operant conditioning tests}

The instrumental learning tests were performed as described in previous studies of our group [90]. Six Skinner boxes were used simultaneously $(12.5 \times 13.5 \times 18.5 \mathrm{~cm}$; MED Associates, St. Albans, VT, USA). Each Skinner box was housed in a sound-attenuating cubicle $(90 \times 55$ $\times 60 \mathrm{~cm})$ constantly exposed to white noise $( \pm 45 \mathrm{~dB})$ and dim light (Cibertec, S.A, Madrid, Spain). The boxes had a trough to receive food pellets (Noyes formula P; $45 \mathrm{mg}$; Sandown Scientific, Hampton, UK) by pressing a lever. Before the test, mouse food availability was monitored for 7 days to reduce initial mouse weight to $85 \%$. First, mice (ZH3: Prnp ${ }^{+/+}=49$ and Prnp ${ }^{Z H 3 / Z H 3}=49$; and ZH1: $\operatorname{Prnp}^{+/+}=10$ and $\operatorname{Prnp}^{Z H 1 / Z H 1}=10$ ) were trained to press the lever to receive food pellets in a fixed-ratio (1:1) schedule. Seven daily sessions $(20 \mathrm{~min} /$ each) were held. The boxes were cleaned with soap and ethanol (30\%) between trials. Obtaining $\geq 20$ pellets for two consecutive sessions was defined as the criterion to assume the learning criteria achievement. Following this first operant conditioning test, we increased the paradigm complexity to test the mice in a more demanding cognitive task for an additional 10 days. Only animals that met the learning criterion were tested (ZH3: Prnp $^{+/+}=24$ and Prnp ${ }^{Z H 3 / Z H 3}=20$; and ZH1: Prnp $^{+/+}=$ 8 and $\left.P r n p^{Z H 1 / Z H 1}=5\right)$. The paradigm consisted of light (ON period) and dark periods (OFF period) randomly distributed during the session. The light was provided by a small light bulb located over the lever. During the ON period $(20 \mathrm{~s})$, lever presses were reinforced with food pellets at a ratio of 1:1. During the OFF period, lever presses were not rewarded and were penalized by adding ten additional seconds $(20 \pm 10 \mathrm{~s})$ to the next ON period. The number of lever presses during the different conditioning paradigms was monitored and recorded 
with the MED-PC program (MED Associates, St. Albans, VT, USA). Statistical analysis was carried out using twoway ANOVA with repeated measures and Bonferroni's multiple comparisons test (GraphPad Prism 8 software). Asterisks indicate significant differences: ${ }^{* *} p<0.01$; and ${ }^{* * * *} p<0.001$. Data are presented as the mean \pm S.E.M. or as a percentage (as indicated in each figure).

\section{Rotarod test}

For this test, a total of 15 mice of 4 months were used $\left(\right.$ Prnp $^{Z H 3 / Z H 3}=8$ and Prnp $\left.{ }^{+/+}=7\right)$. Motor performance was tested using an accelerating rotarod. Mice were pretrained to the task to reach a minimum of $30 \mathrm{~s}$ performance at $5 \mathrm{rpms}$ on the 1st day of testing. In each training run, animals were placed on the rods at an initial speed of $5 \mathrm{rpm}$ for $30 \mathrm{~s}$. After that, the testing consisted of 5 consecutive trials with 15-min inter-trial intervals. Each trial consisted of $30 \mathrm{~s}$ at $5 \mathrm{rpm}$ followed by $5 \mathrm{rpm}$ increases every $15 \mathrm{~s}$ with a cut-off of $5 \mathrm{~min}$. Results are expressed as the mean latency of animals to fall from the rod \pm S.E.M. The statistical analysis was performed with the two-way ANOVA + Bonferroni's multiple comparisons test (GraphPad Prism 8 software).

\section{Object recognition test}

The object recognition test was performed in a homemade arena $(30 \times 25 \times 20 \mathrm{~cm})$, as described [91]. A total of $23 \mathrm{Prnp}^{+/+}$and $24 \mathrm{Prnp}^{\mathrm{ZH} / \mathrm{ZH} 3}$ mice were analyzed. Additionally, 6 Prnp ${ }^{Z H 1 / Z H 1}$ mice were also used with 7 Prnp $^{+/+}$counterparts. The test consisted of four phases of $10 \mathrm{~min} / \mathrm{each}$. First, animals were habituated to the field without any object (habituation session). One hour later, two identical plastic objects were placed in the center of the arena for the training session. A short-term memory test was performed $2-3 \mathrm{~h}$ later by changing one of the objects (see Additional File 4: Fig. S4). ZH1 mouse mobility was expressed as the number of rearing episodes during the habituation session. The arena and the objects were cleaned with soap and 30\% ethanol between trials to remove olfactory cues. Mouse behavior was recorded with a video camera placed over the arena, and these recordings were used to measure the exploratory behavior blindly. Sniffing and gently touching the objects were counted as exploratory behavior. To further support increased anxiety levels in the Prnp ${ }^{Z H 3 / Z H 3}$ mice, fecal bodies left in the maze during the habituation session were counted by the observer once the test subject was removed since it has been demonstrated that highly emotional animals exhibit increased defecation [56]. Statistical analysis was performed with the MannWhitney $U$ non-parametric test (GraphPad Prism 8 software). Data are presented as the mean \pm S.E.M. or as a percentage (indicated in each figure).

\section{Mouse surgery}

A total of 98 adult male (3-5 months) mice were implanted with stimulating and recording electrodes $\left(\right.$ Prnp $^{+/+}=49$ and Prnp $\left.{ }^{\text {ZH3/ZH3 }}=49\right)$. Four of them died during surgery, and 33 mice were excluded because of the inability to obtain reliable and clean recordings. Thus, the experiments were performed with 61 mice $\left(\right.$ Prnp $^{+/+}=31$ and Prnp $\left.{ }^{Z H 3 / Z H 3}=30\right)$. Surgery was performed as described in $[19,92]$. Mice were deeply anesthetized with ketamine $(35 \mathrm{mg} / \mathrm{kg})$ and xylazine $(2 \mathrm{mg} /$ $\mathrm{kg}$ ), and electrodes were aimed at the right dorsal hippocampus. Two recording electrodes were implanted in the stratum radiatum of the CA1 area $(2.2 \mathrm{~mm}$ caudal to Bregma, $1.2 \mathrm{~mm}$ lateral, and $1.3 \mathrm{~mm}$ ventral), and two stimulating electrodes were implanted in the Schaffer collateral pathway of the CA3 region $(1.5 \mathrm{~mm}$ posterior to Bregma, $2 \mathrm{~mm}$ lateral, and $1.3 \mathrm{~mm}$ ventral). Electrodes were made of $50 \mu \mathrm{m}$ Teflon-coated tungsten wires (Advent Research, Eynsham, UK). Electrode localizations were checked according to the field excitatory postsynaptic potential (fEPSP) profile evoked by a single stimulation. A silver wire was fixed to the skull as ground. All the wires were soldered to a six-pin socket (RS Amidata, Madrid, Spain) fixed to the skull with dental cement. Recordings were started at a minimum of 1 week after the surgery.

\section{Electrophysiology recordings}

Animals were consecutively recorded in groups of six individuals since they reach the total number of animals used in each experiment. Each animal was placed in a small plastic cubicle $(5 \times 5 \times 10 \mathrm{~cm})$ inside a large Faraday box $(30 \times 30 \times 20 \mathrm{~cm})$. fEPSPs were recorded with a high impedance probe $\left(2 \times 10^{12} \Omega, 10 \mathrm{pF}\right)$ using differential amplification at a bandwidth of $0.1 \mathrm{~Hz}-10 \mathrm{kHz}$ (P511, Grass-Telefactor, West Warwick, RI, USA). For each experiment, artefactual recordings were discarded. The stimulation intensity threshold of each animal was set with paired-pulse stimulations at $40 \mathrm{~ms}$ of interstimulus interval. The stimulus intensity was set to 40 $60 \%$ of the amount necessary to evoke a suturing response. These intensity values were used for all the experiments.

\section{Paired-pulse stimulation}

For synaptic facilitation experiments, 51 mice $\left(\right.$ Prnp $^{+/+}=$ 27 and $\operatorname{Prnp}^{Z H 3 / Z H 3}=24$ ) were stimulated at Schaffer collaterals with a pair of pulses at different interstimulus intervals $(10,20,40,100,200$, and $500 \mathrm{~ms})$ at 2 $x$ threshold intensities $(\approx 0.2 \mathrm{~mA})$. Threshold values were previously defined for each mouse. As classically defined, threshold values were determined as the intensity evoking fEPSP responses in 50\% of the cases. For all the inter-pulse intervals, the stimulations were repeated 
ten times. Data are represented as the mean percentage increases of fEPSP2 from fEPSP1 recordings (fEPSP2 / fEPSP1 × 100) \pm S.E.M.

\section{Input/output curves}

Schaffer collaterals of 29 mice $\left(\right.$ Prnp $^{+/+}=14$ and $\operatorname{Prnp}^{Z H 3 / Z H 3}=15$ ) were stimulated with paired pulses at 20 increasing intensities (from 0.02 to $0.4 \mathrm{~mA}$, increased in steps of $0.02 \mathrm{~mA}$ ) at $40 \mathrm{~ms}$ of inter-stimulus interval. For all the selected intensities, the stimulations were repeated ten times. Data are represented as the mean of fEPSP slopes $(\mathrm{V} / \mathrm{s}) \pm$ S.E.M. The same data are presented as the mean of paired-pulsed ratio (PP ratio) \pm S.E.M. $\mathrm{PP}$ ratio is the percentage of the increase of the fEPSP2 from fEPSP1 recordings (fEPSP2 / fEPSP1 × 100). The area under the curve (AUC) was calculated from the PP ratio of all the animals using GraphPad Prism 8 software. Statistical analysis was performed using the MannWhitney-Wilcoxon non-parametric test or two-way ANOVA + Bonferroni's multiple comparisons test (GraphPad Prism 8 software). The asterisks indicate significant differences: ${ }^{*} p<0.05$; ${ }^{* *} p<0.01$; and ${ }^{* * *} p<$ 0.001 in the figure.

\section{Long-term potentiation experiments}

For long-term potentiation experiments, 40 mice $\left(\right.$ Prnp $^{+/+}=20$ and Prnp $\left.{ }^{Z H 3 / Z H 3}=20\right)$ were stimulated at Schaffer collaterals. In a first experimental step, fEPSP baseline values were evoked and recorded for $15 \mathrm{~min}$, with paired-pulse stimulus presented every $20 \mathrm{~s}(40 \mathrm{~ms}$ inter-stimulus). Stimulus intensities were selected to evoke fEPSPs of about $0.2-0.3 \mathrm{mV}$ of amplitude (see insets in Fig. 4a,b). Next, LTP was evoked with a highfrequency stimulation (HFS) protocol. HFS consisted of five trains of pulses at a rate of $1 / \mathrm{s}(200 \mathrm{~Hz}, 100 \mathrm{~ms})$ with the same intensity as the baseline recording. The HFS was repeated six times at intervals of $1 \mathrm{~min}$. After the HFS protocol, fEPSPs were recorded, as for baseline, for $1 \mathrm{~h}$. The following 4 days, the recordings were repeated for $30 \mathrm{~min}$. fEPSPs and $1 \mathrm{~V}$ rectangular pulses corresponding to stimulus presentations were saved on a PC using an analog/digital converter (CED 1401 Plus, Cambridge, England). Data were analyzed offline using Spike2 and Signal 5.04 software with homemade representation programs [58]. Collected recordings were represented and analysed offline with the help of commercial (Spike 2 and Signal 5.04) programs following procedures described elsewhere. The slope of collected fEPSPs was computed as its first derivative (volts/ s). Five successive fEPSs were averaged and the mean value of the slope was determined. Data are presented as the mean of the percentage compared to the baseline \pm S.E.M. The statistical analysis was performed using twoway ANOVA + Bonferroni's multiple comparisons test
(GraphPad Prism 8 software). The asterisks and symbols indicate significant differences: ${ }^{*} p<0.05$; ${ }^{* * *} p<0.01$; and ${ }^{* * * *} p<0.001 ;{ }^{\# \#} p<0.01$; and ${ }^{\# \# \#} p<0.001$.

\section{KA-induced epilepsy and seizure analysis}

Adult (3-4 months old) male mice were used for these sets of experiments $\left(\right.$ Prnp $^{+/+}=18$ and Prnp $\left.{ }^{Z H 3 / Z H 3}=20\right)$ essentially as described in [28]. A KA (Sigma-Aldrich, Darmstadt, Germany) solution was freshly prepared for each experiment in $0.1 \mathrm{M}$ phosphate buffer. Mice were injected with $\mathrm{KA}(10 \mathrm{mg} / \mathrm{kg}$ b.w. $)$ three times: at $0 \mathrm{~min}$, $30 \mathrm{~min}$, and $60 \mathrm{~min}$. After the first injection, mice were placed in clean boxes (1-3 mice/box). The presence of epileptic seizures was monitored in situ and recorded with a video camera for $3 \mathrm{~h}$ after drug administration. Seizure severity was scored in grades following the following criteria: grade I-II: hypoactivity and immobility; grade III-IV: hyperactivity and scratching; grade V: loss of balance control and intermittent convulsions; grade VI: continuous seizures and bouncing activity (also reported as blinking episodes or "pop-corn" behavior). Data are presented as the mean \pm S.E.M. or as a percentage (as indicated in each figure). Statistical analysis was performed with the Mann-Whitney $U$ non-parametric test (GraphPad Prism 8 software). The asterisk indicates significant differences: ${ }^{*} p<0.05$ in the figure.

\section{RNAseq}

Hippocampi were extracted, flash frozen on dry ice, and RNA was harvested using RNAEasy Mini kit (Qiagen). Libraries were prepared using the TruSeq Stranded mRNA Sample Prep Kit v2 according to the manufacturer's protocol. Briefly, $500 \mathrm{ng}$ of total RNA was used for poly(A)-mRNA selection using Oligo (dT) magnetic beads and subsequently fragmented to approximately $300 \mathrm{bp}$. cDNA was synthesized using reverse transcriptase (SuperScript II, Invitrogen) and random primers. The second strand of the cDNA incorporated dUTP in place of dTTP. Double-stranded DNA was further used for library preparation. dsDNA was subjected to Atailing and ligation of the barcoded Truseq adapters. All purification steps were performed using AMPure XP Beads. Library amplification was performed with PCR using the primer cocktail supplied in the kit. Final libraries were analyzed using Agilent DNA 1000 chip to estimate the quantity, check the size distribution, and then quantified by qPCR using the KAPA Library Quantification Kit (KapaBiosystems, Merck, Darmstadt, Germany) before amplification Illumina's cBot. Libraries were sequenced $1 \times 50$ bp on Illumina's HiSeq 2500 .

The quality of the fast files was checked using the FastQC software (http://www.bioinformatics.babraham. ac.uk/projects/fastqc/). An estimation of ribosomal RNA in the raw data was obtained with riboPicker [93]. Reads 
were aligned with the STAR mapper [94] to release M14 of the Mus musculus Gencode version of the genome (GRMm38/mm10 assembly) (https://www.gencodegenes. org/mouse/release_M14.html). A raw count of reads per gene was also obtained with STAR (-quantMode TranscriptomeSAM GeneCounts option). The R/Bioconductor package DESeq2 [95, 96] was used to assess differential expression between experimental groups (Wald statistical test + false discovery rate correction). Prior to processing the differential expression analysis, genes for which the sum of raw counts across all samples was less than two were discarded. Deregulated genes with a $p$ adj $<0.05$ were used to disclose relevant pathway alterations in the REACTOME v77 pathway database gene expression. The analysis has been done just with the protein-coding genes. The gene difference was considered biologically relevant if they are upregulated or downregulated with a fold change of $>1.2$ or $<$ 0.85 , respectively. A pathway was considered relevant if it was related to neuronal and/or cerebral functions, showed significance ( $p$ adj $<0.05$ ) and contained more than 10 deregulated genes. The sequencing data have been deposited at the Gene Expression Omnibus (GEO) with accession code: GSE189691 (Matamoros-Angles, A; Hervera, A; Soriano, J; Martí, E; Carulla, P, Llorens, F; Nuvolone, M; Aguzzi, A; Ferrer I; Gruart, A; DelgadoGarcía, JM; Del Río, JA. RNA sequencing of hippocampus of Prnp+/+ and PrnpZH3/ZH3 animals. https:// identifiers.org/geo:GSE189691).

\section{RT-qPCR}

For RT-qPCR validations, cDNA was obtained with a High-Capacity cDNA Reverse Transcription kit (Applied Biosystems) following the supplier's instructions. RTqPCR reactions contained $4.5 \mu \mathrm{L}$ cDNA and mixed with $0.5 \mu \mathrm{L}$ 20X TaqMan Gene Expression Assays and $5 \mu \mathrm{L}$ of 2X TaqMan Universal PCR Master Mix (Applied Biosystems) for a final volume of $10 \mu \mathrm{L}$. TaqMan probes used were as follows: Grin2b Mm00433820_m1, Gabrr2 Mm00433507_m1, Kacnj6 Mm01215650_m1, Kcna1 Mm00439977_s1, Kcnj2 Mm00434616_m1, Kcnq3 Mm00548884_m1 (Applied Biosystems). Actb Mm02619580_g1 and Aars Mm00507627_m1 were used as endogenous controls. The assay was performed using technical duplicates per sample in 384-well optical plates with ABI Prism 7900 Sequence Detection system (Applied Biosystems, Life Technologies) following the supplier's parameters: $50^{\circ} \mathrm{C}$ for $2 \mathrm{~min}, 95^{\circ} \mathrm{C}$ for $10 \mathrm{~min}$, and 40 cycles of $95^{\circ} \mathrm{C}$ for $15 \mathrm{~s}$ and $60^{\circ} \mathrm{C}$ for $1 \mathrm{~min}$. The Sequence Detection Software (SDS version 2.2.2, Applied Biosystems) was used for data processing. It was further analyzed with the $\Delta \Delta \mathrm{Ct}$ method, which consists of obtaining $\Delta \mathrm{Ct}$ by normalizing each target gene to its endogenous control, followed by subtracting the mean- $\Delta \mathrm{Ct}$ of the control group samples to each $\Delta \mathrm{Ct}$ to obtain $\Delta \Delta \mathrm{Ct}$ values, and finally using these $\Delta \Delta \mathrm{Ct}$ values as the negative exponent with base 2 , thereby obtaining fold change per sample.

\section{Fluoro-Jade B staining}

Mice were perfused 7 days after the KA administration with $4 \%$ paraformaldehyde (PFA) dissolved in $0.1 \mathrm{M}$ phosphate buffer $(\mathrm{pH}=7.3-7.4)$. Brains were dissected and postfixed overnight with the same fixative solution. The following day, they were cryoprotected in $0.1 \mathrm{M}$ phosphate buffer containing 30\% sucrose (w/v). After freezing in dry ice, $50-\mu \mathrm{m}$-thick coronal sections were obtained with a freezing microtome (Leica, Wetzlar, Germany). Sections containing the dorsal hippocampus were selected and rinsed in $0.1 \mathrm{M}$ phosphate buffer and mounted on gelatin-coated slides. The slides containing sections were dried at $37^{\circ} \mathrm{C}$ overnight. The following day, they were heated at $50^{\circ} \mathrm{C}$ for $45 \mathrm{~min}$ before staining to improve adhesion. The staining started with pretreatment for $3 \mathrm{~min}$ in absolute alcohol, followed by $1 \mathrm{~min}$ in $70 \%$ ethanol and $1 \mathrm{~min}$ in deionized water. After that, they were oxidized in a solution of $0.06 \% \mathrm{KMnO}_{4}$ for 15 min. Following three rinses $(2 \mathrm{~min} / \mathrm{each})$ in deionized water, they were incubated in a solution of $0.001 \%$ Fluoro-Jade B (Chemicon, Temecula, CA, USA) containing $0.05 \%$ of DAPI in $0.1 \%$ acetic acid for $30 \mathrm{~min}$. Finally, sections were rinsed in deionized water $(3 \mathrm{~min})$, dehydrated with ethanol, cleared with xylene, and coverslipped with Eukitt ${ }^{\mathrm{TM}}$ (Merck, Darmstadt, Germany). Considering that wild-type mice did not displayed Fluoro-Jade B labeled cells in the CA1-CA3 regions after KA treatments and only a very few background could be seen at high magnification and long exposures times (> $500 \mathrm{~ms}$ ), the Fluoro-Jade B fluorescence in the pyramidal layer of the dorsal hippocampal region (4 sections of each mouse, $n=4$ mice per genotype) was photodocumented using an Olympus BX61 epifluorescence microscope equipped with a cooled DP12L camera (Hamburg, Germany). Photomicrographs were obtained using a $\times 40$ objective with identical time exposure between preparations from each wild-type and respective knock-out mouse. No modifications were applied to the obtained pictures. Changes in Fluoro-Jade B labeling were determined by analyzing the corrected total cell fluorescence (CTCF) values (see Matamoros-Angles et al. [97], for details) in the pyramidal layer of hippocampal CA1-3 regions of four mice of each genotype, taking a region of interest of $200 \times 100 \mu \mathrm{m}$ centered in the pyramidal layer, and 4-5 different sections per animals were analyzed and averaged. Data were expressed as mean \pm S.E.M. The statistical analysis of the obtained data was performed using Mann-Whitney $U$ nonparametric test in GraphPad Prism 8 software. A value 
of ${ }^{* * * * *} p<0.001$ was considered statistically significant in the CTCF analysis.

\section{Primary cortical cultures of $\operatorname{Prnp}{ }^{\mathrm{ZH} / \mathrm{ZH} 3}$ and wild-type mice}

Primary cortical cultures were fashioned from E16.5E17.5 Prnp $^{+/+}$and Prnp ${ }^{Z H 3 / Z H 3}$ mouse embryos, as explained elsewhere [98]. Brains were removed from the skull and rinsed in cold Hank's balanced salt solution (HBSS) containing glucose $(6.5 \mathrm{mg} / \mathrm{ml})$. The meninges were removed, and the cortical lobes were isolated. Tissue pieces were treated with trypsin for $15 \mathrm{~min}$ at $37^{\circ} \mathrm{C}$. After the addition of horse serum followed by centrifugation, cells were isolated mechanically with a polished glass pipette after treatment with $0.025 \%$ DNAse for $10 \mathrm{~min}$ at $37^{\circ} \mathrm{C}$. One million cells were plated on a $35-\mathrm{mm}$ diameter glass-bottom gridded culture dish (Ibidi, Martinsried, Germany) previously coated with poly-D-lysine (Sigma-Aldrich). Neurobasal ${ }^{\mathrm{TM}}$ medium supplemented with $6.5 \mathrm{mg} /$ $\mathrm{ml}$ glucose, $2 \mathrm{mM}$ glutamine, penicillin/streptomycin, $5 \%$ of horse serum, and B27 was used as a culture medium (all from Invitrogen-Thermo Fisher Scientific, MA, USA). As Prnp $^{0 / 0}$-derived cells are sensitive to serum removal [99], after $24 \mathrm{~h}$, the serum was reduced to $2.5 \%$. The medium was changed every 2 days. Horse serum was entirely removed on the eighth day of culture.

\section{Calcium imaging in neuronal culture}

Primary cortical neurons were infected $24 \mathrm{~h}$ after seeding with AAV9-Synapsin-GCaMP6f [60] (Watertown, MA, USA). In our cultures, the genetically encoded calcium indicators started to express 3-4 days after infection. Calcium changes in GCaMP6f-expressing neurons were recorded at $8,11,13$, and 15 days in vitro (DIV) using an Olympus IX71 inverted microscope (Olympus, Hamburg, Germany), equipped with an ORCA-Flash 4.0 camera (Hamamatsu Photonics, Japan). During recording, the cells were maintained in a microscope stage incubator at $5 \% \mathrm{CO}_{2}$ and $37{ }^{\circ} \mathrm{C}$ (Okolab S.R.L., Italy). The same region of the culture was recorded throughout the days following the culture dish grid references. Images (1024 $\times 1024$ pixels) were captured using a $\times 20$ objective and $470 \mathrm{~nm}$ wavelength (CoolLED's pE-300 ${ }^{\text {white }}$, Delta Optics, Madrid, Spain) every $100 \mathrm{~ms}$ for 8-10 min using the CellSens $^{\mathrm{TM}}$ software (Olympus) or the Micro-Manager Open Source Microscopy Software (https://micromanager.org). Exposure levels and frequency were maintained between cultures and evaluation days. GCaMP6f activity was measured in four different identified squares of each culture dish during these 4 days.

Neuronal activity traces, spike events, and network bursts The recordings were analyzed offline using two MATLAB $^{\text {TM }}$ toolboxes: NETCAL (www.itsnetcal.com)
$[100,101]$ and NeuroCa [102]. In NeuroCa, an automatic analysis was performed afterward to corroborate obtained NETCAL results. Using NETCAL, a highly contrasted image of the recording's average fluorescence was created, and regions of interest (ROIs) were automatically detected as those objects with a circular shape whose brightness was over a preset threshold. NETCAL and NeuroCa software-rendered a similar number of ROIs and calcium traces. About 400 ROIs, uniformly covering the field of view, were typically identified per recording. The average fluorescence $F_{i}(t)$ in each ROI $i$ along the recording was then extracted, corrected from global drifts and artifacts, and finally normalized as $\left(F_{i}\right.$ $\left.(t)-F_{(0, i)}\right) / F_{(0, i)}=f_{i}(t)$, where $F_{0, i}$ is the background fluorescence of the ROI. The time series of $f_{i}(t)$ was analyzed with NETCAL to infer neuronal activation timing using the Schmitt trigger method. Our analysis used +2 S.E.M. of the baseline noise as the high threshold, +1.5 S.E.M. as the low threshold, and $200 \mathrm{~ms}$ as the minimum event length. Calcium traces were calculated, and raster plots of network activity were then constructed by representing the trains of detected neuronal spikes over time. Next, network bursts were analyzed to quantify the ability of the neuronal networks to exhibit collective dynamics, i.e., the collective activation of a group of neurons in a short time window. Bursts were investigated using two approaches. In the first approach, raster plots of spike events were scanned to detect collective occurrences in which at least $5 \%$ of the neurons in the network fired synchronously within a 500-ms window. This threshold of $5 \%$ was set to disregard random activations that coincided in time. In the second approach, the fluorescence time series of all neurons in the network were averaged. The resulting trace was analyzed with the Schmitt trigger method to detect sufficiently strong fluorescence peaks associated with bursting episodes. Both approaches produced consistent results. Although the detected bursts contained a different number of participating neurons, this information was disregarded in the present analysis and treated later. The total number of detected network bursts divided by the recording duration reflected the culture's activity and was indicated as bursts/min.

The fraction of active neurons in the network was calculated as follows. All detected ROIs were assigned as neurons. After inferring the spike trains, those neurons exhibiting at least two spikes along the recording were considered active, and their number $N_{A}$ was set as a proxy of the healthy population in the neuronal network. The average fraction of active neurons in each condition was then determined as $f=N_{A} / N_{T}$, where $N_{T}$ is the total number of detected ROIs.

At least ten videos of each genotype/day from different culture plates were consecutively analyzed. Data are 
presented as the mean of network burst/min \pm S.E.M. Statistical analysis was performed using two-way ANOVA + Bonferroni's multiple comparisons test (GraphPad Prism 8 software). Asterisks indicate significant differences between $P r n p^{+/+}$and Prnp ${ }^{\mathrm{ZH} 3 / \mathrm{ZH} 3}$ cultures at a given DIV: ${ }^{*} p<0.05$ and ${ }^{* * * *} p<0.001$. The \# symbols indicate significant differences between a given DIV with the initial value at 8 DIV: ${ }^{\# \#} p<0.001$.

\section{Statistical analysis}

All statistical analysis was performed with GraphPad PRISM 8 (GraphPad Software, USA). Unless otherwise stated, data is plotted as the mean \pm SEM. All experiments were performed three times unless specified. Normality of the distributions was checked via Shapiro-Wilk test. All tests performed were two-sided, and adjustments for multiple comparisons and/or significantly different variances (Fisher's $F$ ) applied were indicated. All data analysis was performed blind to the experimental group by two independent experimenters. Unless otherwise stated, sample size was chosen in order to ensure a power of at least 0.8 , with a type I error threshold of 0.05 , in view of the minimum effect size that was expected.

\begin{abstract}
Abbreviations
AMPA: Alpha-amino-3-hydroxy-5-methyl-4-isoxazolepropionic acid; ANOVA: Analysis of variance; AUC: Area under the ROC curve; CA3CA1: Cornnu ammonis 3 and 1 of the hippocampus:; CEEA: Ethical Committee for Animal Experimentation; CTCF: Corrected total cell. fluorescence; fEPSP: Field excitatory postsynaptic potential; FG: Flanking genes; GECl: Genetically encoded calcium indicator; GLUK2: Glutamate ionotropic receptor kainate type subunit 2; GPI: Glycosylphosphatidylinositol; HFS: High-frequency stimulation; KA: Kainate; LTP: Long-term potentiation; mGluR5: Metabotropic glutamate receptor 5; MK-801: NMDA antagonist; NMDA-R: N-methyl-D-aspartate receptor; PFA: Paraformaldehyde; Prnp: Cellular prion protein gene; PrPC: Cellular prion protein; PSD-95: Post synaptic density protein of 95 kD; PTZ: Pentylenetetrazol; ROl: Region of interest; SCJD: Sporadic Creutzfeldt-Jakob disease; SEM: Standard deviation of the mean; TALEN: Transcription activator-like effector nuclease
\end{abstract}

\section{Supplementary Information}

The online version contains supplementary material available at https://doi. org/10.1186/s12915-021-01203-0.

Additional file 1: Figure S1. Prnp ${ }^{Z H 3 / Z H 3}$ mice showed similar nestbuilding behavior to wild-type mice. $\boldsymbol{a}$, Representative images of nests constructed by $\operatorname{Prnp}^{+/+}$(left) and Prnp ${ }^{Z H 3 / Z H 3}$ mice (right). b, Quantification illustrating the mean of the nest score (see Material and Methods for details). Data are presented as mean \pm S.E.M. Source data and individual data values are available in Additional file 10.

Additional file 2: Figure S2. Prnp ${ }^{Z H 1 / Z H 1}$ mice failed to acquire an instrumental learning test in the Skinner box test using a fixed ratio (1:1)

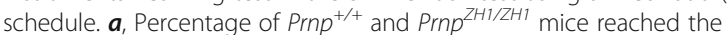
selected criterion during the training sessions. $\boldsymbol{b}$, Task accuracy ((lever presses during light ON - lever presses during the light OFF) / Total number of lever presses) during the light ON / light OFF conditioning paradigm. Data are presented as a percentage in $\boldsymbol{a}$ and as mean \pm S.E.M. in $\boldsymbol{b}$. Source data and individual data values are available in Additional file 10
Additional file 3: Figure S3. $P r n p^{Z H 3 / Z H 3}$ mice have deficits in acquiring instrumental learning but not motor impairment in the Rotarod test. After a training session in the Rotarod, mice were tested two consecutive days with 5 sessions in each. Latency of mice to fall (sec.) from the Rotarod in the first day $(\boldsymbol{a})$ or in the second $(\boldsymbol{b})$. Data are presented as mean \pm S.E.M.. ${ }^{*} p<0.05$ and ${ }^{* *} p<0.01$, two-way ANOVA + Bonferroni's multiple comparisons test. Source data and individual data values are available in Additional file 10

Additional file 4: Figure S4. Stressed-like behavior in $P r n p^{Z H 3 / Z H 3}$ mice impairing object recognition test performance. Prnp ${ }^{Z \mathrm{H1} / \mathrm{ZH1}}$ mice also showed stressed-like behavior and failed to acquire short-term memory. $\boldsymbol{a}$, Scheme of object recognition protocol that consisted of 3 sessions (10 min each). First, mice were habituated in the empty arena. One hour later, they were placed again in the arena with two identical objects for the training session. Finally, 2-3 h later, they were once more placed in the arena, replacing one object with a novel one for the short-term memory test. Fecal bodies (Prnp ${ }^{\mathrm{ZH} 3 / \mathrm{ZH} 3}$ ) and rearing episodes (Prnp ${ }^{\mathrm{ZH} / \mathrm{ZH1}}$ ) were counted in the habituation session as an indicator of animal stress. $\boldsymbol{b}$, Number of fecal bodies generated per animal (Prnp ${ }^{+/+}$and Prnp ${ }^{\text {ZH3/ZH3 }}$ ) during the habituation session. Data are presented as mean \pm S.E.M. $\boldsymbol{c}$ - $\boldsymbol{d}$ Time that $\operatorname{Prnp}^{+/+}(\boldsymbol{c})$, and $\operatorname{Prnp}^{Z \mathrm{H} / Z \mathrm{ZH} 3}(\boldsymbol{d})$ mice interacted with the objects in the short-term test. Data are presented as the percentage of mice interacting with the object in each time interval (0 to $35 \mathrm{~s}$ ). $\boldsymbol{e}$, Number of rearing episodes in the habituation session $\left(P_{r n p^{+/+}}\right.$and $\left.P r n p^{Z H 1 / Z H 1}\right) . \boldsymbol{f}-\boldsymbol{g}$, Relative time that the two exposed objects are explored to the total time invested. Object $1\left(\mathrm{O}_{1}\right)$ and object $1^{\prime}\left(\mathrm{O}_{1}{ }^{\prime}\right)$ in the training session $(\boldsymbol{f})$ and number, and object $1\left(\mathrm{O}_{1}\right)$ and object $2\left(\mathrm{O}_{2}\right)$ in the short-term memory test $(\boldsymbol{g})$. Data are presented as percentages in $\boldsymbol{C}-\boldsymbol{D}$ and as mean \pm S.E.M. in $\boldsymbol{b}, \boldsymbol{e}, \boldsymbol{f}, \boldsymbol{g} .{ }^{*} p<0.05$ and ${ }^{* *} p<0.001$, Mann-Whitney $U$ non-parametric test. Source data and individual data values are available in Additional file 10.

Additional file 5: Table S1. List of the protein-coding significantly downregulated genes in Prnp ${ }^{Z H 3 / Z H 3}$ hippocampus compared to Prnp ${ }^{+/+}$.

Additional file 6: Table S2. List of the protein-coding significantly upregulated genes in Prnp ${ }^{Z H 3 / Z H 3}$ hippocampus compared to $\mathrm{Prnp}^{+/+}$.

Additional file 7: Figure S5. Gene ontology of the genes significantly downregulated and upregulated in Prnp ${ }^{Z \mathrm{H} 3 / \mathrm{ZH} 3}$ hippocampus compared to $\operatorname{Prnp}^{+/+} \cdot \boldsymbol{a}$, Volcano plot of the protein-coding genes analyzed in the RNAseq $(\sim 16.000)$. In the $X$-axis is plotted the Fold change $(\log 2)$ and in the $Y$-axis the padj $(-\log 10)$. The red line separates the significantly expressed genes (padj <0,05). The blue lines indicate the 0,85 and 1,2 fold changes. $\boldsymbol{b}$, Gene ontology analysis of the downregulated and upregulated genes with the Reactome software (see Materials and Methods for details). Validation of the main genes altered by RT-qPCR: Grin2b (c), Gabrr2 (d), Kcnj6 (e), Kcnal (f), Kcnj2 (g), and Kcnq3 (h). Data are presented as mean \pm S.E.M. ${ }^{*} p<0.05$ and ${ }^{* * *} p<0.001$. Source data and individual data values are available in Additional file 10.

Additional file 8: Movie S1. Representative movie of $\mathrm{Prnp}^{+/+}$(bottom and up-left) and $P r n p^{Z H 3 / Z H 3}$ (middle and up-right) mouse behavior after KA (middle and bottom) and PBS (top) administration. Note the blinking and seizure episodes suffered by the Prnp $p^{Z H 3 / Z H 3}$ mice treated with KA (labeled with asterisks at the beginning of the video). Source data and individual data values are available in Additional file 10.

Additional file 9: Figure S6. Images of the original, uncropped blots for Figs. $1 \mathrm{~A}$ and $6 \mathrm{~A}$.

Additional file 10. Excel file 1. File providing individual data values for all figures from the manuscript.

\section{Acknowledgements}

The authors thank Tom Yohannan for editorial advice and Miriam SeguraFeliu, María Sánchez-Enciso, and José M. González-Martín for their technical help.

\section{Authors' contributions}

A M-A, A.H., J.S., P.C., E.M., and F.L. performed most of the experiments. A MA. and A.H. participated in all the experiments, performing and designing, and contributed equally to this project. P.C performed the behavior experiments. J.S. analyzed and interpreted the calcium imaging data. E.M. and F.L. 
planned and organized the RNAseq and performed the gene ontology anaIysis. A.G. and J.M D-G developed the electrophysiological experiments. J.A.D.R., A.G., J.M. D.-G., A.A., M.N., and I.F designed and supervised the study. J.M. D.-G., and J.A.D.R analyzed the results. J.A.D.R. and J.M. D.-G. wrote the draft and circulated it among the authors. The authors read and approved the final manuscript.

\section{Funding}

This research was supported by PRPSEM Project with ref. RTI2018-099773-BI00 from MCINN/AEI/10.13039/501100011033/ FEDER "Una manera de hacer Europa", the CERCA Programme, and the Commission for Universities and Research of the Department of Innovation, Universities, and Enterprise of the Generalitat de Catalunya (SGR2017-648), CIBERNED (CMED2018-2) to JADR and IF. The project leading to these results received funding from the "Ia Caixa" Foundation (ID 100010434) under the agreement LCF/PR/HR19/ 52160007 and the María de Maeztu Unit of Excellence (Institute of Neurosciences, University of Barcelona) MDM-2017-0729 to JADR. JS was supported by FIS2016-78507-C2-2-P from (MCIU/FEDER/AEI), SGR2017-1061 from the Generalitat de Catalunya, and the European Union's Horizon 2020 research and innovation program under the grant agreement No. 713140 (MESOBRAIN). Support was also received from MINECO (BFU2017-82375-R), and Junta de Andalucía (BIO-122, UPO-1250734, and P18-FR-823) grants to AG and JMDG. F.LL. was supported by Instituto Carlos III (grant PI19-00144). A.MA. was supported by the Tatiana Pérez de Guzmán el Bueno Foundation.

\section{Availability of data and materials}

All data generated or analysed during this study are included in this published article and additional information files. RNAseq data have been deposited at the Gene Expression Omnibus (GEO) with accession code: GSE189691. (Matamoros-Angles, A; Hervera, A; Soriano, J; Martí, E; Carulla, P, Llorens, F; Nuvolone, M; Aguzzi, A; Ferrer I; Gruart, A; Delgado-García, JM; Del Río, JA. RNA sequencing of hippocampus of Prnp ${ }^{+/+}$and Prnp $p^{Z H 3 / Z H 3}$ animals. https://identifiers.org/geo:GSE189691). Source data for all figures have been provided in Additional file 10. Uncropped blots from Figs. 1 and 6 are available in Additional file 9

\section{Declarations}

\section{Ethics approval and consent to participate}

All experiments were performed following the protocols and guidelines of the Ethical Committee for Animal Experimentation (CEEA) of the University of Barcelona. CEEA of the University of Barcelona approved the protocol for using animals in this study (CEEA approval \#276/16 and 141/15). Behavioral and electrophysiological studies were performed following the guidelines of the European Union Council (2010/276:33-79/EU) and current Spanish regulations (BOE 34:11370-421, 2013) for the use of laboratory animals in chronic experiments. Experiments were also approved by the Ethics Committee for Animal Care and Handling of the Pablo de Olavide University (UPO-JA 06/03/2018/025).

\section{Consent for publication}

Not applicable.

\section{Competing interests}

The authors declare that they have no competing interests.

\section{Author details}

${ }^{1}$ Molecular and Cellular Neurobiotechnology, Institute of Bioengineering of Catalonia (IBEC), Parc Científic de Barcelona, Barcelona, Spain. ${ }^{2}$ Department of Cell Biology, Physiology, and Immunology, University of Barcelona, Barcelona, Spain. ${ }^{3}$ CIBERNED (Network Centre of Biomedical Research of Neurodegenerative Diseases), Institute of Health Carlos III, Barcelona, Spain. ${ }^{4}$ Institute of Neuroscience, University of Barcelona, Barcelona, Spain. ${ }^{5}$ Institute of Neuropathology, University Medical Center Hamburg-Eppendorf, Hamburg, Germany. ${ }^{6}$ Departament de Física de la Materia Condensada, University of Barcelona, Barcelona, Spain. ${ }^{7}$ Institute of Complex Systems (UBICS), University of Barcelona, Barcelona, Spain. ${ }^{8}$ Department of Biomedicine, University of Barcelona, Barcelona, Spain. ${ }^{9}$ Bioinformatics and Genomics, Center for Genomic Regulation, Barcelona, Spain. ${ }^{10}$ Department of Neurology, University Medical School, Göttingen, Germany. ${ }^{11}$ Bellvitge Biomedical Research Institute (IDIBELL), L'Hospitalet de Llobregat, Catalonia,
Spain. ${ }^{12}$ Institute of Neuropathology, University Hospital of Zürich, Zürich, Switzerland. ${ }^{13}$ Amyloidosis Center, Foundation IRCCS Policlinico San Matteo, Department of Molecular Medicine, University of Pavia, Pavia, Italy. ${ }^{14}$ Senior Consultant, Bellvitge University Hospital, IDIBELL (Bellvitge Biomedical Research (entre), L'Hospitalet de Llobregat, Spain. ${ }^{15}$ Department of Pathology and Experimental Therapeutics, University of Barcelona, Barcelona, Spain. ${ }^{16}$ Division of Neurosciences, Pablo de Olavide University, 41013 Seville, Spain.

Received: 25 March 2021 Accepted: 2 December 2021

Published online: 13 January 2022

\section{References}

1. Barmada S, Piccardo P, Yamaguchi K, Ghetti B, Harris DA. GFP-tagged prion protein is correctly localized and functionally active in the brains of transgenic mice. Neurobiol Dis. 2004;16(3):527-37. https://doi.org/10.1016/j. nbd.2004.05.005

2. Moser M, Colello RJ, Pott U, Oesch B. Developmental expression of the prion protein gene in glial cells. Neuron. 1995;14(3):509-17. https://doi.org/1 0.1016/0896-6273(95)90307-0.

3. Adle-Biassette H, Verney C, Peoc'h K, Dauge MC, Razavi F, Choudat $L$, et al. Immunohistochemical expression of prion protein (PrPC) in the human forebrain during development. J Neuropathol Exp Neurol. 2006;65(7):698706. https://doi.org/10.1097/01.jnen.0000228137.10531.72

4. Tremblay P, Bouzamondo-Bernstein E, Heinrich C, Prusiner SB, DeArmond SJ. Developmental expression of PrP in the post-implantation embryo. Brain Res. 2007;1139:60-7. https://doi.org/10.1016/j.brainres.2006.12.055.

5. Bailly Y, Haeberle AM, Blanquet-Grossard F, Chasserot-Golaz S, Grant N, Schulze T, et al. Prion protein (PrPc) immunocytochemistry and expression of the green fluorescent protein reporter gene under control of the bovine PrP gene promoter in the mouse brain. J Comp Neurol. 2004;473(2):244-69. https://doi.org/10.1002/cne.20117.

6. Prusiner SB, DeArmond SJ. Prion diseases and neurodegeneration. Ann Rev Neurosci. 1994;17(1):311-39. https://doi.org/10.1146/annurev.ne.17.030194. 001523.

7. Aguzzi A. Molecular pathology of prion diseases. Vox Sang. 2000;78(Suppl 2):25.

8. Linden R, Martins VR, Prado MA, Cammarota M, Izquierdo I, Brentani RR. Physiology of the prion protein. Physiol Rev. 2008;88(2):673-728. https://doi. org/10.1152/physrev.00007.2007.

9. Wulf MA, Senatore A, Aguzzi A. The biological function of the cellular prion protein: an update. BMC Biol. 2017;15(1):34. https://doi.org/10.1186/s12915017-0375-5

10. Legname $G$. Elucidating the function of the prion protein. PLoS Pathog. 2017;13(8):e1006458. https://doi.org/10.1371/journal.ppat.1006458.

11. del Rio JA, Gavin R. Functions of the cellular prion protein, the end of Moore's law, and Ockham's razor theory. Prion. 2016;10(1):25-40. https://doi. org/10.1080/19336896.2015.1126038.

12. Steele $A D$, Lindquist $S$, Aguzzi $A$. The prion protein knockout mouse: a phenotype under challenge. Prion. 2007;1(2):83-93. https://doi.org/10.4161/ pri.1.2.4346.

13. Watts JC, Bourkas MEC, Arshad $\mathrm{H}$. The function of the cellular prion protein in health and disease. Acta Neuropathol. 2018;135(2):159-78. https://doi. org/10.1007/s00401-017-1790-y.

14. Roucou X, Gains M, LeBlanc AC. Neuroprotective functions of prion protein. J Neurosci Res. 2004;75(2):153-61. https://doi.org/10.1002/jnr.10864.

15. Gavin R, Lidon L, Ferrer I, Del Rio JA. The quest for cellular prion protein functions in the aged and neurodegenerating brain. Cells. 2020;9(3). https:// doi.org/10.3390/cells9030591.

16. Chiarini LB, Freitas AR, Zanata SM, Brentani RR, Martins VR, Linden R. Cellular prion protein transduces neuroprotective signals. EMBO J. 2002;21(13):331726. https://doi.org/10.1093/emboj/cdf324.

17. Paitel E, Sunyach C, Alves da Costa C, Bourdon JC, Vincent B, Checler F. Primary cultured neurons devoid of cellular prion display lower responsiveness to staurosporine through the control of p53 at both transcriptional and post-transcriptional levels. J Biol Chem. 2004;279(1):6128. https://doi.org/10.1074/jbc.M310453200.

18. Paitel $E$, Fahraeus $R$, Checler F. Cellular prion protein sensitizes neurons to apoptotic stimuli through Mdm2-regulated and p53-dependent caspase 3like activation. J Biol Chem. 2003;278(12):10061-6. https://doi.org/10.1074/ jbc.M211580200. 
19. Rangel A, Madronal N, Gruart A, Gavin R, Llorens F, Sumoy L, et al. Regulation of $\mathrm{GABA}(\mathrm{A})$ and glutamate receptor expression, synaptic facilitation and long-term potentiation in the hippocampus of prion mutant mice. PloS one. 2009;4(10):e7592. https://doi.org/10.1371/journal.pone. 0007592.

20. Goetzl EJ, Peltz CB, Mustapic M, Kapogiannis D, Yaffe K. Neuron-derived plasma exosome proteins after remote traumatic brain injury. J Neurotrauma. 2020;37(2):382-8. https://doi.org/10.1089/neu.2019.6711.

21. Leng B, Sun H, Zhao J, Liu Y, Shen T, Liu W, et al. Plasma exosomal prion protein levels are correlated with cognitive decline in PD patients. Neurosci Lett. 2020;723:134866. https://doi.org/10.1016/j.neulet.2 020.134866

22. Llorens F, Ansoleaga B, Garcia-Esparcia P, Zafar S, Grau-Rivera O, LopezGonzalez l, et al. PrP mRNA and protein expression in brain and $\operatorname{PrP}(c)$ in CSF in Creutzfeldt-Jakob disease MM1 and W2. Prion. 2013;7(5):383-93. https://doi.org/10.4161/pri.26416.

23. Scalabrino G, Veber D, De Giuseppe R, Roncaroli F. Low levels of cobalamin, epidermal growth factor, and normal prions in multiple sclerosis spinal cord. Neuroscience. 2015;298:293-301. https://doi.org/10.1016/j.neuroscience.201 5.04.020.

24. Büeler H, Fischer M, Lang Y, Bluethmann H, Lipp HP, DeArmond SJ, et al. Normal development and behaviour of mice lacking the neuronal cellsurface PrP protein. Nature. 1992;356(6370):577-82. https://doi.org/10.1038/3 56577a0.

25. Lledo PM, Tremblay P, DeArmond SJ, Prusiner SB, Nicoll RA. Mice deficient for prion protein exhibit normal neuronal excitability and synaptic transmission in the hippocampus. Proc Natl Acad Sci U S A. 1996;93(6): 2403-7. https://doi.org/10.1073/pnas.93.6.2403.

26. Nuvolone M, Kana V, Hutter G, Sakata D, Mortin-Toth SM, Russo G, et al. SIRPalpha polymorphisms, but not the prion protein, control phagocytosis of apoptotic cells. J Exper Med. 2013;210(12):2539-52. https://doi.org/10.1 084/jem.20131274.

27. de Almeida CJ, Chiarini LB, da Silva JP, ES PM, Martins MA, Linden R. The cellular prion protein modulates phagocytosis and inflammatory response. Leukoc Biol. 2005;77(2):238-46. https://doi.org/10.1189/jlb.1103531.

28. Carulla P, Llorens F, Matamoros-Angles A, Aguilar-Calvo P, Espinosa JC, Gavin $R$, et al. Involvement of $\operatorname{Pr} P(C)$ in kainate-induced excitotoxicity in several mouse strains. Sci Rep. 2015;5(1):11971. https://doi.org/10.1038/ srep11971.

29. Sparkes RS, Simon M, Cohn VH, Fournier RE, Lem J, Klisak I, et al. Assignment of the human and mouse prion protein genes to homologous chromosomes. Proc Natl Acad Sci U S A. 1986;83(19):7358-62. https://doi. org/10.1073/pnas.83.19.7358

30. Rangel A, Burgaya F, Gavin R, Soriano E, Aguzzi A, Del Rio JA. Enhanced susceptibility of Prnp-deficient mice to kainate-induced seizures, neuronal apoptosis, and death: role of AMPA/kainate receptors. J Neurosci Res. 2007; 85(12):2741-55. https://doi.org/10.1002/jnr.21215.

31. Walz R, Amaral OB, Rockenbach IC, Roesler R, Izquierdo I, Cavalheiro EA, et al. Increased sensitivity to seizures in mice lacking cellular prion protein. Epilepsia. 1999;40(12):1679-82. https://doi.org/10.1111/j.1528-1157.1999.tb01 583.x

32. Striebel JF, Race B, Pathmajeyan M, Rangel A, Chesebro B. Lack of influence of prion protein gene expression on kainate-induced seizures in mice: studies using congenic, coisogenic and transgenic strains. Neuroscience. 2013;238:11-8. https://doi.org/10.1016/j.neuroscience.2013.02.004.

33. Brown EJ, Frazier WA. Integrin-associated protein (CD47) and its ligands. Trends Cell Biol. 2001;11(3):130-5. https://doi.org/10.1016/S0962-8924(00)01906-1.

34. Nuvolone M, Paolucci M, Sorce S, Kana V, Moos R, Matozaki T, et al. Prion pathogenesis is unaltered in the absence of SIRPalpha-mediated "don't-eatme" signaling. PloS One. 2017;12(5):e0177876. https://doi.org/10.1371/journa I.pone.0177876.

35. Adao-Novaes J, Valverde RHF, Landemberger MC, Silveira MS, Simoes-Pires EN, Lowe J, et al. Substrain-related dependence of Cu(I)-ATPase activity among prion protein-null mice. Brain Res. 2020;1727:146550. https://doi. org/10.1016/j.brainres.2019.146550.

36. Encalada SE, Szpankowski L, Xia CH, Goldstein LS. Stable kinesin and dynein assemblies drive the axonal transport of mammalian prion protein vesicles. Cell. 2011;144(4):551-65. https://doi.org/10.1016/j.cell.2011.01.021.

37. Khosravani H, Zhang Y, Tsutsui S, Hameed S, Altier C, Hamid J, et al. Prion protein attenuates excitotoxicity by inhibiting NMDA receptors. J Cell Biol. 2008;181(3):551-65. https://doi.org/10.1083/jcb.200711002.
38. Carulla P, Bribián A, Rangel A, Gavín R, Ferrer I, Caelles C, et al. Neuroprotective role of PrPC against kainate-induced epileptic seizures and cell death depends on the modulation of JNK3 activation by GluR6/7-PSD95 binding. Mol Biol Cell. 2011;22(17):3041-54. https://doi.org/10.1091/mbc. e11-04-0321.

39. Ferreira DG, Temido-Ferreira M, Vicente Miranda H, Batalha VL, Coelho JE, Szego EM, et al. Alpha-synuclein interacts with $\operatorname{PrP}(C)$ to induce cognitive impairment through mGluR5 and NMDAR2B. Nat Neurosci. 2017;20(11): 1569-79. https://doi.org/10.1038/nn.4648.

40. Collinge J, Whittington MA, Sidle KC, Smith CJ, Palmer MS, Clarke AR, et al. Prion protein is necessary for normal synaptic function. Nature. 1994; 370(6487):295-7. https://doi.org/10.1038/370295a0.

41. Manson JC, Hope J, Clarke AR, Johnston A, Black C, MacLeod N. PrP gene dosage and long term potentiation. Neurodegeneration. 1995;4(1):113-4.

42. Criado JR, Sanchez-Alavez M, Conti B, Giacchino JL, Wills DN, Henriksen SJ, et al. Mice devoid of prion protein have cognitive deficits that are rescued by reconstitution of PrP in neurons. Neurobiol Dis. 2005;19(1-2):255-65. https://doi.org/10.1016/j.nbd.2005.01.001.

43. Curtis J, Errington M, Bliss T, Voss K, MacLeod N. Age-dependent loss of PTP and LTP in the hippocampus of PrP-null mice. Neurobiol Dis. 2003;13(1):5562. https://doi.org/10.1016/S0969-9961(03)00017-2

44. Maglio LE, Martins VR, Izquierdo I, Ramirez OA. Role of cellular prion protein on LTP expression in aged mice. Brain Res. 2006;1097(1):11-8. https://doi. org/10.1016/j.brainres.2006.04.056.

45. Schmitz M, Greis C, Ottis P, Silva CJ, Schulz-Schaeffer WJ, Wrede A, et al. Loss of prion protein leads to age-dependent behavioral abnormalities and changes in cytoskeletal protein expression. Mol Neurobiol. 2014;50(3):92336. https://doi.org/10.1007/s12035-014-8655-3.

46. Lipp HP, Stagliar-Bozicevic M, Fischer M, Wolfer DP. A 2-year longitudinal study of swimming navigation in mice devoid of the prion protein: no evidence for neurological anomalies or spatial learning impairments. Behav Brain Res. 1998:95(1):47-54. https://doi.org/10.1016/S0166-4328(97)00209-X.

47. Coitinho AS, Roesler R, Martins VR, Brentani RR, Izquierdo I. Cellular prion protein ablation impairs behavior as a function of age. Neuroreport. 2003; 14(10):1375-9. https://doi.org/10.1097/00001756-200307180-00019.

48. Fainstein N, Dori D, Frid K, Fritz AT, Shapiro I, Gabizon R, et al. Chronic progressive neurodegeneration in a transgenic mouse model of prion disease. Front Neurosci. 2016;10:510. https://doi.org/10.3389/fnins.2016. 00510.

49. Manson JC, Clarke AR, Hooper ML, Aitchison L, McConnell I, Hope J. 129/Ola mice carrying a null mutation in PrP that abolishes mRNA production are developmentally normal. Mol Neurobiol. 1994;8(2-3):121-7. https://doi.org/1 $0.1007 / B F 02780662$.

50. Nuvolone M, Hermann M, Sorce S, Russo G, Tiberi C, Schwarz P, et al. Strictly co-isogenic C57BL/6 J-Prnp-/- mice: A rigorous resource for prion science. J Exper Med. 2016;213(3):313-27. https://doi.org/10.1084/jem.20151610.

51. Nuvolone M, Sorce S, Paolucci M, Aguzzi A. Extended characterization of the novel co-isogenic C57BL/6 J Prnp(-/-) mouse line. Amyloid. 2017;24(sup1): $36-7$

52. Gadotti VM, Bonfield SP, Zamponi GW. Depressive-like behaviour of mice lacking cellular prion protein. Behav Brain Res. 2012;227(2):319-23. https:// doi.org/10.1016/j.bbr.2011.03.012.

53. Salazar SV, Gallardo C, Kaufman AC, Herber CS, Haas LT, Robinson S, et al. Conditional deletion of Prnp rescues behavioral and synaptic deficits after disease onset in transgenic Alzheimer's disease. J Neurosci. 2017;37(38): 9207-21. https://doi.org/10.1523/JNEUROSCI.0722-17.2017.

54. Schmitz M, Zafar S, Silva CJ, Zerr I. Behavioral abnormalities in prion protein knockout mice and the potential relevance of $\operatorname{PrP}(C)$ for the cytoskeleton. Prion. 2014;8(6):381-6. https://doi.org/10.4161/19336896.2014.983746.

55. Jirkof P. Burrowing and nest building behavior as indicators of well-being in mice. J Neurosci Methods. 2014;234:139-46. https://doi.org/10.1016/j. jneumeth.2014.02.001

56. Seibenhener ML, Wooten MC. Use of the open field maze to measure locomotor and anxiety-like behavior in mice. J Vis Exp. 2015;96(96):e52434 https://doi.org/10.3791/52434.

57. Steinert JR. Prion protein as a mediator of synaptic transmission. Commun Integr Biol. 2015;8(4):e1063753. https://doi.org/10.1080/19420889.2015.1063 753.

58. Madroñal N, Gruart A, Delgado-García JM. Differing presynaptic contributions to LTP and associative learning in behaving mice. Front Behav Neurosci. 2009;3:7. https://doi.org/10.3389/neuro.08.007.2009. 
59. Stafstrom CE, Carmant L. Seizures and epilepsy: an overview for neuroscientists. In: Cold Spring Harbor perspectives in medicine. vol. 5. New York: Cold Spring Harbor Laboratory Press; 2015.

60. Chen TW, Wardill TJ, Sun Y, Pulver SR, Renninger SL, Baohan A, et al. Ultrasensitive fluorescent proteins for imaging neuronal activity. Nature. 2013:499(7458):295-300. https://doi.org/10.1038/nature12354.

61. Nazor KE, Seward T, Telling GC. Motor behavioral and neuropathological deficits in mice deficient for normal prion protein expression. Biochim Biophys Acta. 2007;1772(6):645-53. https://doi.org/10.1016/j.bbadis.2007.04 004.

62. Bult A, Lynch CB. Nesting and fitness: lifetime reproductive success in house mice bidirectionally selected for thermoregulatory nest-building behavior. Behav Genet. 1997;27(3):231-40. https://doi.org/10.1023/A:102 5610130282.

63. Gaskill BN, Karas AZ, Garner JP, Pritchett-Corning KR. Nest building as an indicator of health and welfare in laboratory mice. J Vis Exp. 2013;82(82): 51012. https://doi.org/10.3791/51012.

64. Simon P, Dupuis $R$, Costentin J. Thigmotaxis as an index of anxiety in mice. Influence of dopaminergic transmissions. Behav Brain Res. 1994;61(1):59-64. https://doi.org/10.1016/0166-4328(94)90008-6.

65. Lobao-Soares B, Walz R, Carlotti CG Jr, Sakamoto AC, Calvo F, Terzian AL, et al. Cellular prion protein regulates the motor behaviour performance and anxiety-induced responses in genetically modified mice. Behav Brain Res. 2007;183(1):87-94. https://doi.org/10.1016/j.bbr.2007.05.027.

66. Nico PB, de-Paris F, Vinade ER, Amaral OB, Rockenbach I, Soares BL, et al. Altered behavioural response to acute stress in mice lacking cellular prion protein. Behav Brain Res. 2005;162(2):173-81. https://doi.org/10.1016/j.bbr.2 005.02.003.

67. Janner DR, de Lima EV, da Silva RT, Clarke JR, Linden R. Dissociation of genotype-dependent cognitive and motor behavior in a strain of aging mice devoid of the prion protein. Behav Brain Res. 2021;411:113386. https:// doi.org/10.1016/j.bbr.2021.113386.

68. Rial D, Duarte FS, Xikota JC, Schmitz AE, Dafre AL, Figueiredo CP, et al. Cellular prion protein modulates age-related behavioral and neurochemical alterations in mice. Neuroscience. 2009;164(3):896-907. https://doi.org/10.1 016/j.neuroscience.2009.09.005

69. Russo SJ, Nestler EJ. The brain reward circuitry in mood disorders. Nat Rev Neurosci. 2013;14(9):609-25. https://doi.org/10.1038/nrn3381.

70. Anacker C, Hen R. Adult hippocampal neurogenesis and cognitive flexibility — linking memory and mood. Nat Rev Neurosci. 2017;18(6):335-46. https:// doi.org/10.1038/nrn.2017.45.

71. Jackman SL, Regehr WG. The mechanisms and functions of synaptic facilitation. Neuron. 2017;94(3):447-64. https://doi.org/10.1016/j.neuron.2017.02.047.

72. Kanner AM. Anxiety disorders in epilepsy: the forgotten psychiatric comorbidity. Epilepsy Currents. 2011;11(3):90-1. https://doi.org/10.5698/153 5-7511-11.3.90.

73. Medel-Matus JS, Shin D, Sankar R, Mazarati A. Kindling epileptogenesis and panic-like behavior: their bidirectional connection and contribution to epilepsy-associated depression. Epilepsy Behav E\&B. 2017;77:33-8. https:// doi.org/10.1016/j.yebeh.2017.10.001.

74. Ratte S, Vreugdenhil M, Boult JK, Patel A, Asante EA, Collinge J, et al. Threshold for epileptiform activity is elevated in prion knockout mice. Neuroscience. 2011;179:56-61. https://doi.org/10.1016/j.neuroscience.2011.01.053.

75. McKhann GM 2nd, Wenzel HJ, Robbins CA, Sosunov AA, Schwartzkroin PA. Mouse strain differences in kainic acid sensitivity, seizure behavior, mortality, and hippocampal pathology. Neuroscience. 2003;122(2):551-61. https://doi. org/10.1016/S0306-4522(03)00562-1.

76. Royle SJ, Collins FC, Rupniak HT, Barnes JC, Anderson R. Behavioural analysis and susceptibility to CNS injury of four inbred strains of mice. Brain Res. 1999:816(2):337-49. https://doi.org/10.1016/S0006-8993(98)01122-6.

77. Meador KJ. The basic science of memory as it applies to epilepsy. Epilepsia. 2007;48(Suppl 9):23-5. https://doi.org/10.1111/j.1528-1167.2007.01396.x.

78. Reid IC, Stewart CA. Seizures, memory and synaptic plasticity. Seizure. 1997; 6(5):351-9. https://doi.org/10.1016/S1059-1311(97)80034-9.

79. You H, Tsutsui S, Hameed S, Kannanayakal TJ, Chen L, Xia P, et al. Abeta neurotoxicity depends on interactions between copper ions, prion protein and N-methyl-D-aspartate receptors. Proc Natl Acad Sci U S A. 2012;109(5): 1737-42. https://doi.org/10.1073/pnas.1110789109.

80. Watt NT, Taylor DR, Kerrigan TL, Griffiths HH, Rushworth JV, Whitehouse IJ, et al. Prion protein facilitates uptake of zinc into neuronal cells. Nat Commun. 2012;3(1):1134. https://doi.org/10.1038/ncomms2135.
81. Gavin R, Urena J, Rangel A, Pastrana MA, Requena JR, Soriano E, et al. Fibrillar prion peptide PrP(106-126) treatment induces Dab1 phosphorylation and impairs APP processing and Abeta production in cortical neurons. Neurobiol Dis. 2008;30(2):243-54. https://doi.org/10.1016/j. nbd.2008.02.001

82. Pantera B, Bini C, Cirri P, Paoli P, Camici G, Manao G, et al. PrPc activation induces neurite outgrowth and differentiation in PC12 cells: role for caveolin-1 in the signal transduction pathway. J Neurochem. 2009;110(1): 194-207. https://doi.org/10.1111/j.1471-4159.2009.06123.x.

83. Loubet D, Dakowski C, Pietri M, Pradines E, Bernard S, Callebert J, et al. Neuritogenesis: the prion protein controls beta1 integrin signaling activity. FASEB J. 2012;26(2):678-90. https://doi.org/10.1096/fj.11-185579.

84. Amin L, Nguyen XT, Rolle IG, D'Este E, Giachin G, Tran TH, et al. Characterization of prion protein function by focal neurite stimulation. J Cell Sci. 2016;129(20):3878-91. https://doi.org/10.1242/jcs.183137.

85. Benvegnu S, Roncaglia P, Agostini F, Casalone C, Corona C, Gustincich S, et al. Developmental influence of the cellular prion protein on the gene expression profile in mouse hippocampus. Physiol Genom. 2011;43(12):71125. https://doi.org/10.1152/physiolgenomics.00205.2010.

86. Platzer K, Yuan H, Schutz H, Winschel A, Chen W, Hu C, et al. GRIN2B encephalopathy: novel findings on phenotype, variant clustering, functional consequences and treatment aspects. J Med Genet. 2017;54(7):460-70. https://doi.org/10.1136/jmedgenet-2016-104509.

87. Platzer K, Lemke JR. GRIN2B-related neurodevelopmental disorder. In: Adam MP, Ardinger HH, Pagon RA, Wallace SE, LJH B, Stephens K, Amemiya A, editors. GeneReviews((R)). Seattle (WA): University of Washington; 1993.

88. Cahill L. Why sex matters for neuroscience. Nat Rev Neurosci. 2006;7(6):47784. https://doi.org/10.1038/nrn1909.

89. Deacon RM. Assessing nest building in mice. Nat Protoc. 2006;1(3):1117-9. https://doi.org/10.1038/nprot.2006.170.

90. Madronal N, Lopez-Aracil C, Rangel A, del Rio JA, Delgado-Garcia JM, Gruart A. Effects of enriched physical and social environments on motor performance, associative learning, and hippocampal neurogenesis in mice. PloS One. 2010;5(6):e11130. https://doi.org/10.1371/journal.pone.0011130.

91. Clarke JR, Cammarota M, Gruart A, Izquierdo I, Delgado-García JM. Plastic modifications induced by object recognition memory processing. Proc Natl Acad Sci U S A. 2010;107(6):2652-7. https://doi.org/10.1073/pnas.09150591 07.

92. Medrano-Fernandez A, Delgado-Garcia JM, Del Blanco B, Llinares M, Sanchez-Campusano R, Olivares $\mathrm{R}$, et al. The epigenetic factor CBP is required for the differentiation and function of medial ganglionic eminence-derived interneurons. Mol Neurobiol. 2018;56(6):4440-54. https:// doi.org/10.1007/s12035-018-1382-4.

93. Schmieder R, Lim YW, Edwards R. Identification and removal of ribosomal RNA sequences from metatranscriptomes. Bioinformatics. 2012;28(3):433-5. https://doi.org/10.1093/bioinformatics/btr669.

94. Dobin A, Davis CA, Schlesinger F, Drenkow J, Zaleski C, Jha S, et al. STAR: ultrafast universal RNA-seq aligner. Bioinformatics. 2013;29(1):15-21. https:// doi.org/10.1093/bioinformatics/bts635.

95. Love Ml, Huber W, Anders S. Moderated estimation of fold change and dispersion for RNA-seq data with DESeq2. Genome Biol. 2014;15(12):550. https://doi.org/10.1186/s13059-014-0550-8.

96. Huber W, Carey VJ, Gentleman R, Anders S, Carlson M, Carvalho BS, et al. Orchestrating high-throughput genomic analysis with Bioconductor. Nat Methods. 2015;12(2):115-21. https://doi.org/10.1038/nmeth.3252.

97. Matamoros-Angles A, Gayosso LM, Richaud-Patin Y, di Domenico A, Vergara C, Hervera A, et al. iPS cell cultures from a Gerstmann-Straussler-Scheinker patient with the Y218N PRNP mutation recapitulate tau pathology. Mol Neurobiol. 2018:55(4):3033-48. https://doi.org/10.1007/s12035-017-0506-6.

98. Urrea L, Segura-Feliu M, Masuda-Suzukake M, Hervera A, Pedraz L, Garcia Aznar JM, et al. Involvement of cellular prion protein in alpha-synuclein transport in neurons. Mol Neurobiol. 2018;55(3):1847-60. https://doi.org/10.1 007/s12035-017-0451-4.

99. Nishimura T, Sakudo A, Hashiyama Y, Yachi A, Saeki K, Matsumoto Y, et al. Serum withdrawal-induced apoptosis in Zrchl prion protein (PrP) gene-deficient neuronal cell line is suppressed by PrP, independent of Doppel. Microbiol Immunol. 2007;51(4):457-66. https://doi.org/10.1111/j.1348-0421.2007.tb03920.x.

100. Teller S, Tahirbegi IB, Mir M, Samitier J, Soriano J. Magnetite-amyloidbeta deteriorates activity and functional organization in an in vitro model for Alzheimer's disease. Sci Rep. 2015;5(1):17261. https://doi.org/1 $0.1038 /$ srep 17261 
101. Orlandi JG, Stetter O, Soriano J, Geisel T, Battaglia D. Transfer entropy reconstruction and labeling of neuronal connections from simulated calcium imaging. PloS One. 2014;9(6):e98842. https://doi.org/10.1371/journal. pone.0098842.

102. Jang MJ, Nam Y. NeuroCa: integrated framework for systematic analysis of spatiotemporal neuronal activity patterns from large-scale optical recording data. Neurophotonics. 2015;2(3):035003. https://doi.org/10.1117/1.NPh.2.3.03 5003

\section{Publisher's Note}

Springer Nature remains neutral with regard to jurisdictional claims in published maps and institutional affiliations.

Ready to submit your research? Choose BMC and benefit from:

- fast, convenient online submission

- thorough peer review by experienced researchers in your field

- rapid publication on acceptance

- support for research data, including large and complex data types

- gold Open Access which fosters wider collaboration and increased citations

- maximum visibility for your research: over $100 \mathrm{M}$ website views per year

At $B M C$, research is always in progress.

Learn more biomedcentral.com/submissions 